\title{
Magnetic Properties and Redox State of Impact Glasses: A Review and New Case Studies from Siberia
}

\author{
Pierre Rochette ${ }^{1, *} \oplus$, Natalia S. Bezaeva ${ }^{2,3}$, Andrei Kosterov ${ }^{4} \oplus$, Jérôme Gattacceca ${ }^{1}$, \\ Victor L. Masaitis ${ }^{5}$, Dmitry D. Badyukov ${ }^{6}$, Gabriele Giuli ${ }^{7}{ }^{\circ}$, Giovani Orazio Lepore ${ }^{8}(\mathbb{D}$ and \\ Pierre Beck ${ }^{9}$ \\ 1 Aix Marseille Université, CNRS, IRD, Coll. France, INRA, CEREGE, 13545 Aix-en-Provence, France; \\ gattacceca@cerege.fr \\ 2 Institute of Geology and Petroleum Technologies, Kazan Federal University, 4/5 Kremlyovskaya Str., \\ 420008 Kazan, Russia; bezaeva@gmail.com \\ 3 Institute of Physics and Technology, Ural Federal University, 19 Mira Str., 620002 Ekaterinburg, Russia \\ 4 St. Petersburg State University, 199034 St. Petersburg, Russia; a.kosterov@spbu.ru \\ 5 A.P. Karpinsky Russian Geological Research Institute (VSEGEI), Sredny prospect 74, \\ 199106 St. Petersburg, Russia; vcmsts@mail.ru \\ 6 V.I. Vernadsky Institute of Geochemistry and Analytical Chemistry, Russian Academy of Sciences, \\ 19 Kosygin str., 119991 Moscow, Russia; badyukov@geokhi.ru \\ 7 School of Science and Technology-Geology division, University of Camerino, Via Gentile III da Varano, \\ 62032 Camerino (MC), Italy; gabriele.giuli@unicam.it \\ 8 CNR-IOM-OGG c/o ESRF, 71 Avenue des Martyrs CS 40220, F-38043 Grenoble, France; lepore@esrf.fr \\ 9 Université Grenoble Alpes, CNRS, IPAG, UMR5274, 38041 Grenoble, France; \\ pierre.beck@univ-grenoble-alpes.fr \\ * Correspondence: rochette@cerege.fr; Tel.: +33-442971562
}

Received: 26 February 2019; Accepted: 11 May 2019; Published: 15 May 2019

\begin{abstract}
High velocity impacts produce melts that solidify as ejected or in-situ glasses. We provide a review of their peculiar magnetic properties, as well as a new detailed study of four glasses from Siberia: El'gygytgyn, Popigai, urengoites, and South-Ural glass (on a total of 24 different craters or strewn-fields). Two types of behavior appear: 1) purely paramagnetic with ferromagnetic impurities at most of the order of $10 \mathrm{ppm}$; this corresponds to the five tektite strewn-fields (including the new one from Belize), urengoites, and Darwin glass. Oxidation state, based in particular on X-ray spectroscopy, is mostly restricted to $\mathrm{Fe}^{2+} ; 2$ ) variable and up to strong ferromagnetic component, up to the $1 \mathrm{wt} \%$ range, mostly due to substituted magnetite often in superparamagnetic state. Accordingly, bulk oxidation state is intermediate between $\mathrm{Fe}^{2+}$ and $\mathrm{Fe}^{3+}$, although metallic iron, hematite, and pyrrhotite are sometimes encountered. Various applications of these magnetic properties are reviewed in the field of paleomagnetism, magnetic anomalies, recognition of glass origin, and formation processes.
\end{abstract}

Keywords: magnetic properties; impact glasses; redox state; Popigai impact glasses; El'gygytgyn impact glasses; urengoites; South-Ural glass

\section{Introduction}

Various types of silicate glass occur in nature [1] and may show exotic iron-bearing inclusions representative of a wide range of redox state [2-4]. Impact generated glasses, having often recorded particularly high pressures and temperatures ( $>10 \mathrm{GPa}$ and $>1700{ }^{\circ} \mathrm{C}$; see [5]) on a short time scale (seconds) and endured equally fast quenching, may yield original magnetic properties that we will describe in the present review. 
Hypervelocity impacts on the Earth surface generate deformation, metamorphism, and melting of the target rocks (e.g., [5]). The melted material can be subsequently fragmented and/or mixed with unmelted material. It may also be ejected outside the crater as liquid masses, injected in the target rocks as dikes, or remain in the crater as a melt sheet. They may be subsequently altered by the impact-induced hydrothermalism. Depending on these modalities, and especially on cooling rate, the rock derived from this melted material may be a pure glass (case of fully melted material rapidly cooled during ballistic ejection, like tektites), or a more or less cryptocrystalline material mixed with unmelted material, with variable proportions of glass, crystals grown from the melt, and unmelted material. In this review on the magnetic properties of impact glasses, the term 'impact glass' will be restricted to impact generated rocks (or large pockets within these rocks) that are mainly in a glassy state at a macroscopic scale. Therefore, we will not treat impactites that contain only small or comminuted fraction of glass or former glass (altered by hydrothermalism or crystallized by slow cooling). These impactites may correspond to suevite or other types of breccia, in particular impact melt dikes often used to perform paleomagnetic dating of impact craters. In fact, a recent review on this subject has been performed by Gilder et al. [6]. Therefore, we will mostly restrict this review to impact glasses with the above definition, still including a few cases, where the melt has, partly-to-totally, crystallized in a microcrystalline rock.

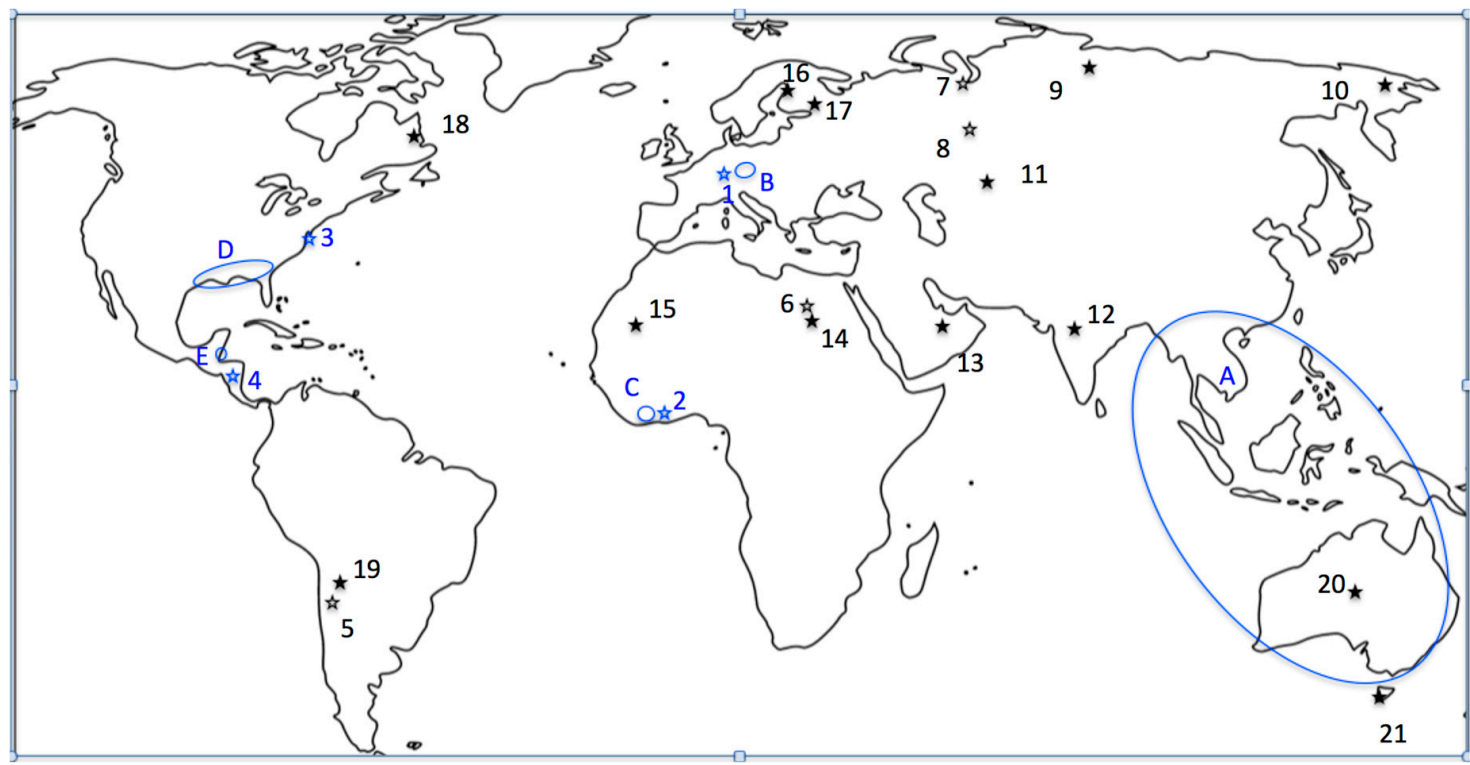

Figure 1. Map of tektite fields (blue contours: A-australasites; B-moldavites; C-ivoirites; D-bediasite-georgiaites; E-belizites), craters of possible origin for tektites (blue star: 1-Ries; 2-Bosumtwi; 3-Chesapeake Bay; 4-Pantasma), other impact glasses without known source crater (black open star: 5-atacamaites; 6-LDG; 7-urengoites; 8-Ural glass) or with known source crater (black filled star: 9-Popigai; 10-El'gygytgyn; 11-irghizites; 12-Lonar; 13-Wabar; 14-Kamil; 15-Aouelloul; 16-Lapajarvi; 17-Janisjarvi; 18-Mistastin; 19-Monturaqui; 20-Henbury; 21-Darwin glass).

The most peculiar and studied impact glasses are tektites. These correspond to (almost) pure glasses that have been ejected far away from their impact source (distance larger than $100 \mathrm{~km}$ and up to $11,000 \mathrm{~km}$, e.g., [7]). These distal materials, besides showing typical splash forms due to their transport in air or vacuum, have quite distinctive properties. This differentiates them from other impact glasses that are found near or inside their source crater. Only five tektite (and three microtektite) strewn fields have been identified on Earth (Figure 1), the largest field by far being the Australasian one [1,8]. The latter is the only confirmed strewn field for which a source crater has not been identified. On the other hand, impact glasses have been found within or around a significant proportion of the $>190$ impact 
craters identified on the Earth. A few impact glasses have been found unrelated to a source crater but on a rather limited surface (thus not corresponding to tektites) and are thus enigmatic, the most spectacular case being the Libyan desert glass (LDG). The typical size for ballistically ejected glasses is centimetric, with maximum size hardly exceeding $10 \mathrm{~cm}$.

The purpose of the present paper, besides a summary of early studies, is to present a synthesis review of the magnetic properties of impact glasses, updating [9] using recent publications [10-12] as well as new results. These include a specific effort on glasses from Siberia (site 7-10 in Figure 1) either associated to a known crater (Popigai and El'gygytgyn) or not (Urengoite and South-Ural glass; [13]). We will also review the oxidation state (based on XANES and EXAFS data) and petrography of magnetic minerals in those glasses.

\section{Early Studies}

The magnetic properties of tektites were first studied by Sigamony [14], who reported the paramagnetic susceptibility of one Australasian tektite from Indonesia, at $98 \times 10^{-9} \mathrm{~m}^{3} / \mathrm{kg}$, and noted that this susceptibility was isotropic. Later, Senftle and Thorpe [15] reported the high field paramagnetic susceptibility $\left(\chi_{\mathrm{hf}}\right)$ of 22 Australasian tektites, between 64 and $99 \times 10^{-9} \mathrm{~m}^{3} / \mathrm{kg}$ (average: 84 ), as well as on 7 North American tektites, and 2 moldavites. Besides one LDG and one Aouelloul glass were reported. All those samples show negligible saturation magnetization $\left(\mathrm{M}_{\mathrm{S}}\right.$, measured on a high field Curie balance using 1-10 mg samples, with a sensitivity better than $10^{-4} \mathrm{Am}^{2} / \mathrm{kg}$ ). Several other glasses (Georgiaite, Australasian microtektite, Tikal glass) were measured later using the same technique [16-18].

In two $\mathrm{PhD}$ theses $[19,20]$ aimed at testing the paleomagnetic potential of tektites (mostly Australasian), a very different measurement technique was used: a superconducting magnetometer, allowing to measure natural and saturation remanence on much larger, i.e., more representative samples (in the $10 \mathrm{~g}$ range) with a sensitivity of $10^{-8} \mathrm{Am}^{2} / \mathrm{kg}$ (for a $10 \mathrm{~g}$ sample). Furthermore, low field susceptibility $(\chi)$ was also estimated by measuring magnetization in a $28 \mu \mathrm{T}$ field, frozen into the superconducting shield. They obtained a mean $\chi$ of $(79 \pm 6) \times 10^{-9} \mathrm{~m}^{3} / \mathrm{kg}$ for australasites, in agreement with $\chi_{\mathrm{hf}}$ measured in [15], supporting a paramagnetic origin for susceptibility. Saturation remanence $\left(\mathrm{M}_{\mathrm{RS}}\right)$ of tektite was usually of the order of $10^{-6} \mathrm{Am}^{2} / \mathrm{kg}$, except for Muong Nong tektites (i.e., layered australasite from central Indochina) that yielded $\mathrm{M}_{\mathrm{RS}}$ in the (5-200) $\times 10^{-6} \mathrm{Am}^{2} / \mathrm{kg}^{\mathrm{range}}$.

Werner and Boradaile [21] measured also susceptibility of tektites on large samples (1-10 g range) using a low field AC susceptibility bridge, on 152 australasites (mostly from Australia, with a mean $\chi$ at $82 \pm 10 \times 10^{-9} \mathrm{~m}^{3} / \mathrm{kg}$ ) and 15 moldavites. Contrary to previous studies, they reported $\mathrm{M}_{\mathrm{S}}$ in the $10^{-3}-10^{-2} \mathrm{Am}^{2} / \mathrm{kg}$ range, using an AGFM magnetometer with few $\mathrm{mg}$ samples, and also large $\mathrm{M}_{\mathrm{RS}}$. Finally, Rochette et al. [9] reported new measurements on all five tektite fields, as well as on LDG and five types of non tektite splash-form impact glasses (called tektoids). They also developed the study of the ferromagnetic contribution in their samples, and showed that the high $\mathrm{M}_{\mathrm{S}}$ reported in tektites in [21] were artifacts of the AGFM system (likely faulty sample holder subtraction). They also confirm $\mathrm{M}_{\mathrm{RS}}$ of tektites is of the order of $10^{-6} \mathrm{Am}^{2} / \mathrm{kg}$.

\section{Measurements and Samples}

We obtained new data for this paper using two different approaches:

1) measuring on site the magnetic susceptibility of two large collections of tektites and impact glasses (collection of the Natural History Museum of Leyden, and the personal Belizite collection of Jean Cornec) using a SM150 susceptibility meter (operating field $320 \mathrm{~A} / \mathrm{m}$ at $1 \mathrm{kHz}$ frequency) which, by measuring simultaneously susceptibility and mass, can process very large collections. Using sample mass above $5 \mathrm{~g}$ can obtain a noise level of the order of $10^{-9} \mathrm{~m}^{3} / \mathrm{kg}$. This target mass was sometimes obtained by pooling specimens in a single measurement;

2) Obtaining samples from various collections and measuring them in the laboratory (CEREGE, Aix-en-Provence, or Russia: Institute of Earth Physics RAS, Moscow and St Petersburg State University, 
St Petersburg). Low-field magnetic susceptibilities at two frequencies (F1 = $1 \mathrm{kHz}$ and F3 $=16 \mathrm{kHz}$, both at 200 A/m) were measured using an Agico MFK1 bridge. Reported values are at F1 frequency and we computed the frequency dependence as $\mathrm{fd} \%=\left(\chi_{\mathrm{F} 1}-\chi_{\mathrm{F} 3}\right) / \chi_{\mathrm{F} 1} \times 100$. Susceptibility versus temperature curves were obtained by heating under argon flow using the CS3 attachment. Hysteresis data were obtained on a Princeton Measurements vibrating sample magnetometer (VSM) with maximum field of 1 Tesla. High-field susceptibility ( $\chi_{h f}$ of mostly paramagnetic origin) was computed from the above $0.7 \mathrm{~T}$ part of the cycle. Natural and saturation remanence were measured with a $2 \mathrm{G}$ Enterprises superconducting magnetometer. Low temperature remanence curves for urengoites, South-Ural glass, and selected Popigai samples were measured using a Quantum design magnetic property measurement system MPMS 3 instrument in St. Petersburg. The saturation isothermal remnant magnetization (SIRM) acquired in a $5 \mathrm{~T}$ field at $1.8 \mathrm{~K}$ after zero field cooling (ZFC) and cooling in a strong (5 T) field (FC), respectively, was traced during the subsequent warming to $300 \mathrm{~K}$ in zero field. SIRM acquired at $300 \mathrm{~K}$ was measured during the cooling-warming cycle between 300 and $1.8 \mathrm{~K}$, also in zero field. Both experiments were carried out with temperature sweeping at $2 \mathrm{~K} / \mathrm{min}$ in the VSM mode ( 6000 points per temperature sweep from $1.8 \mathrm{~K}$ to $300 \mathrm{~K})$ for Popigai samples, and in the DC mode ( 350 point per sweep) for urengoites and South-Ural glass.

Microprobe analyses of South-Ural glass were carried out at IGEM RAS (Moscow, Russia) using JEOL8200. Water content of the South-Ural glass was determined in Grenoble using Fourier transform infra-red (FTIR) transmission microscopy with a VERTEX V70 spectrometer coupled to a Hyperion 3000 infrared microscope (see [11] for further details on the methodology). XAS measurements at the K-edge of Fe were performed at the LISA CRG beamline (BM-08) [22] at the European Synchrotron Radiation Facility (ESRF, Grenoble - France). Samples were measured using a pair of Si (311) flat monochromator crystals, providing an energy resolution $(\Delta \mathrm{E} / \mathrm{E})$ of $\approx 4 \times 10^{-5}$, corresponding to an incoming beam energy bandwidth of $\approx 0.3 \mathrm{eV}$ at $7 \mathrm{keV}$. Si coated focusing mirrors $\left(\mathrm{E}_{\text {cutoff }} \approx 16 \mathrm{KeV}\right.$ ) were used for harmonic rejection, providing a beam of a roughly circular spot with a diameter of $\approx 200 \mu \mathrm{m}$. Measurements were performed on urengoite sample U1 in the fluorescence mode by means of a 12-element solid state (high purity Germanium) detector [23]. The step size in the pre-edge and in the XANES region was 0.1 and $0.3 \mathrm{eV}$, respectively. The post-edge EXAFS region of the spectrum was acquired with a fixed k step of $0.03 \AA^{-1}$ up to a maximum value of $13 \AA^{-1}$. Measurements were carried out at room temperature. Standard procedures [24] were followed for background removal, spline modeling of bare atomic background, edge step normalization using a region far above the edge, and energy calibration using the software ATHENA [25]. The energy has been calibrated by means of a Fe K-edge XANES spectrum of a Fe metallic foil and imposing the edge energy of Fe to equal $7112.0 \mathrm{eV}$. Pre-edge peak data were extracted and fitted according to the procedure reported by [26-28].

\section{Results and Discussion}

\subsection{Essentially Paramagnetic Glass: Tektites and Darwin Glass}

As demonstrated by previous literature (see introduction) using comparison of high-field and low-field susceptibilities, and the match of average $\chi$ values with predicted paramagnetic plus diamagnetic signal assuming all iron into $\mathrm{Fe}^{2+}$ form (Figure 2 redrawn from [9]), tektites as well as Darwin glass are essentially paramagnetic. As these materials have rather limited range in Fe amount, it leads to a narrow susceptibility range, with a standard deviation relative to mean (i.e., coefficient of variation CF) in the 19-24\% range (case of Darwin glass, bediasite, and moldavite) or even in the $3-12 \%$ range (other tektite fields, see Table 1 ). This situation is due to the fact that Fe is essentially under the form of $\mathrm{Fe}^{2+}$, based on EXAFS and XANES investigations [27,29-31]. In that case, neither magnetite nor metal can form in significant amounts during solidification of the melt. 


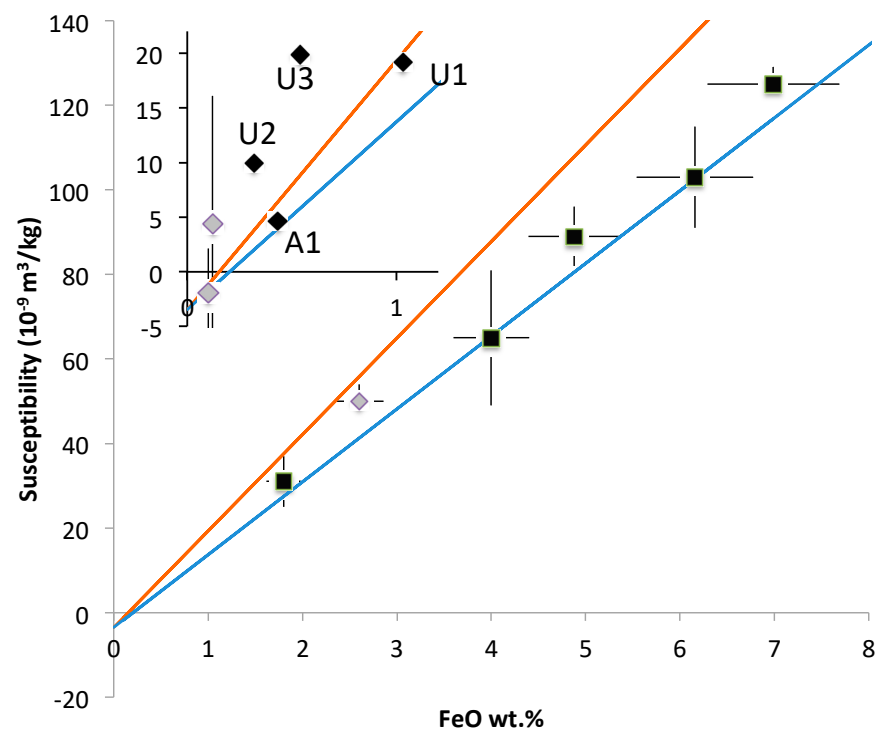

Figure 2. Magnetic susceptibility versus iron amount for tektite (black) and Darwin glass (grey), with theoretical curve for paramagnetic $\mathrm{Fe}^{2+}$ and $\mathrm{Fe}^{3+}$ (in blue and red, respectively), updated after [9]. Inset: iron poor glasses: LDG (grey), urengoite (U1, U2, U3), South-Ural glass (A1).

Table 1. Magnetic susceptibility of tektites and Darwin glass ordered by FeO amount after [9] and this work, excluding anomalies over two times the average for australasite and belizite (see text). ${ }^{*}$ and ${ }^{* *}$ : comparison with data from [20] and [21]. $\mathrm{N}$ is number of measurements (can be pooled specimens, or several specimens from one sample). When known the diameter in $\mathrm{km}$ of the source crater is indicated within brackets.

\begin{tabular}{|c|c|c|c|c|}
\hline Strewnfield & Mean $\chi\left(10^{-9} \mathrm{~m}^{3} / \mathrm{kg}\right)$ & $\begin{array}{l}\text { Coefficient of } \\
\text { Variation (\%) }\end{array}$ & $\chi$ Range & $\mathbf{N}$ \\
\hline Moldavite (24) & 31 & 19 & 25 to 60 & 39 \\
\hline Moldavite * & 26 & 19 & 15 to 60 & 31 \\
\hline Moldavite ${ }^{* *}$ & 35 & 34 & 23 to 78 & 15 \\
\hline Darwin (1.2) & 53 & 23 & 34 to 79 & 45 \\
\hline Bediasite-Georgiaite (40) & 65 & 23 & 43 to 129 & 65 \\
\hline Bediasite-Georgiaite * & 70 & 32 & 49 to 88 & 12 \\
\hline Australasite S. China & 87 & 3 & 74 to 94 & 668 \\
\hline Muong Nong & 93 & 10 & 81 to 107 & 20 \\
\hline Cambodgia, Laos and Thailand & 88 & 7 & 76 to 104 & 40 \\
\hline Vietnam & 93 & 10 & 82 to 128 & 55 \\
\hline Indonesia & 102 & 7 & 81 to 125 & 215 \\
\hline Phillipines & 94 & 7 & 79 to 129 & 77 \\
\hline Australia & 86 & 8 & 73 to 94 & 22 \\
\hline Australasite * & 79 & 8 & 54 to 94 & 111 \\
\hline Australasite ${ }^{* *}$ & 82 & 10 & 57 to 103 & 152 \\
\hline Ivoirite & 103 & 12 & 62 to 138 & 109 \\
\hline Ivoirite * (10) & 103 & 4 & 99 to 107 & 4 \\
\hline Belizite (14?) & 125 & 3 & 112-193 & 1120 \\
\hline
\end{tabular}

As our last study of australasites [9] relied only on the 152 samples, mostly from Australia, reported in [21], we attempted to obtain a much larger database allowing discussion of geographic variability among the australasite strewnfield. Indeed, Donofrio [20], using his database of 111 geographically well-distributed samples proposed that tektites from Indonesia and Malaysia are significantly more magnetic than the ones from the rest of the strewnfield. This was already visible in [15] data on 22 australasites (see their Figure 1). 
To test the homogeneity of $\chi$ on a single locality we measured 668 samples from a site in South China (Maoming) and obtained a very narrow range of $\chi: 87 \pm 3 \times 10^{-9} \mathrm{~m}^{3} / \mathrm{kg}$, i.e., with a standard deviation 3 times smaller than that from the database [21]. The only outlier (over twice the mean) appeared to be due to an inclusion of hardened oxide rich soil within a large bubble connected with the exterior. Indeed, Donofrio [20] already pointed out that the main source for higher than normal magnetic signal (susceptibility or remanence) was soil impurities encrusted on the surface. Therefore, they thoroughly cleaned their samples before measurement.

At the Leyden museum, we measured 572 splash-form tektites using SM150 instrument and found only 11 anomalies (defined as values higher than two times the mean), 1 from the Philippines and 10 from Indonesia. These samples, all visibly incrusted with brown red material, were brought to the CEREGE laboratory for further cleaning using a metal needle under a binocular microscope for the large embedded encrustation, as well as subsequent ultrasonic cleaning in diluted hydrochloric acid. This cleaning resulted in large decrease of $\chi$, turning back nearly to normal values. Apart from these anomalies, one may still observe that data from Indonesia, and to a lesser extent the Philippines, are higher than for Indochina and Australia (Figure 3 and Table 1). This agrees with the results of [20] on Indonesia versus other sources. We also note that, within Indochina, the samples from Vietnam (only 48 samples) have also significantly higher $\chi$, equaling the Philippines average. Based on the fact that soils from Indonesia, the Philippines, and Vietnam are mainly derived from volcanic rocks, while the rest of Indochina, China, and Australia are mainly non-volcanic, our average value differences may be due to a widespread small magnetic soil contamination. On the other hand, the non-anomalous samples from Indonesia, the Philippines, and Vietnam appeared visually devoid of soil contamination during measurement, while the database [20] was obtained on thoroughly cleaned samples. The dispersion of data according to geographic provenance is also consistent with a genuine distinction of Indonesia, the Philippines, and Vietnam with respect to the rest of the strewn-field (Figure 3). We therefore leave open the possibility of a genuine regional variation of $\chi$ within australasites, either due to higher $\mathrm{Fe}$ amount (plus eventually minor paramagnetic elements such as $\mathrm{Mn}, \mathrm{Cr}$, etc.) or higher ferromagnetic contamination (see discussion below).

We also obtained a database on nearly 4000 specimens (pooled in 1120 measurements) of belizites using the SM150. Only 30 anomalies ( $\chi$ higher than two times the mean) were detected, that is less than $1 \%$ of the whole population. Excluding these anomalies leads to an average $\chi$ of $125 \pm 4 \times 10^{-9} \mathrm{~m}^{3} / \mathrm{kg}$, i.e., with a coefficient of variation identical to the South China case, again confirming the extremely high homogeneity of tektites, except very minor anomalies. The belizite anomalies (with $\chi$ up to $57 \times 10^{-6} \mathrm{~m}^{3} / \mathrm{kg}$, median at $1.1 \times 10^{-6} \mathrm{~m}^{3} / \mathrm{kg}$ ) have been subjected to further investigation in the laboratory, showing that they contain variable amounts of titanomagnetite inclusions. These anomalous samples will be further described in a forthcoming publication.

As already pointed out measurements of saturation remanence $\left(\mathrm{M}_{\mathrm{RS}}\right)$ of tektite (except for Muong Nong and anomalous belizites) and Darwin glass yield values of the order of $10^{-6} \mathrm{Am}^{2} / \mathrm{kg}$, at most $[9,20]$. This means that ferromagnetic impurities, either magnetite or metal, should be in amounts less than $1 \mathrm{ppm}$, assuming that $\mathrm{M}_{\mathrm{RS}} / \mathrm{M}_{\mathrm{S}}$ is above 0.01 and 0.004 for magnetite and metal $\left(\mathrm{M}_{\mathrm{S}}\right.$ of 92 and $250 \times 10^{-6} \mathrm{Am}^{2} / \mathrm{kg}$ ), respectively. The contribution to $\chi$ corresponding to $1 \mathrm{ppm}$ of ferromagnetic impurities is $0.5 \times 10^{-9} \mathrm{~m}^{3} / \mathrm{kg}$, which further grounds the essentially paramagnetic nature of tektite susceptibility. Still, inclusions of metallic iron have been described in Australasian tektites of anomalous color and texture [32,33] from the Philippines and South Vietnam (Dalat). There is thus the possibility to find such anomalous samples by surveying the magnetic susceptibility of large collections; in Vietnam, Chao et al. [32] reported two anomalous samples over more than 1500 examined; in the Philippines it was 330 anomalies over several thousand samples. 


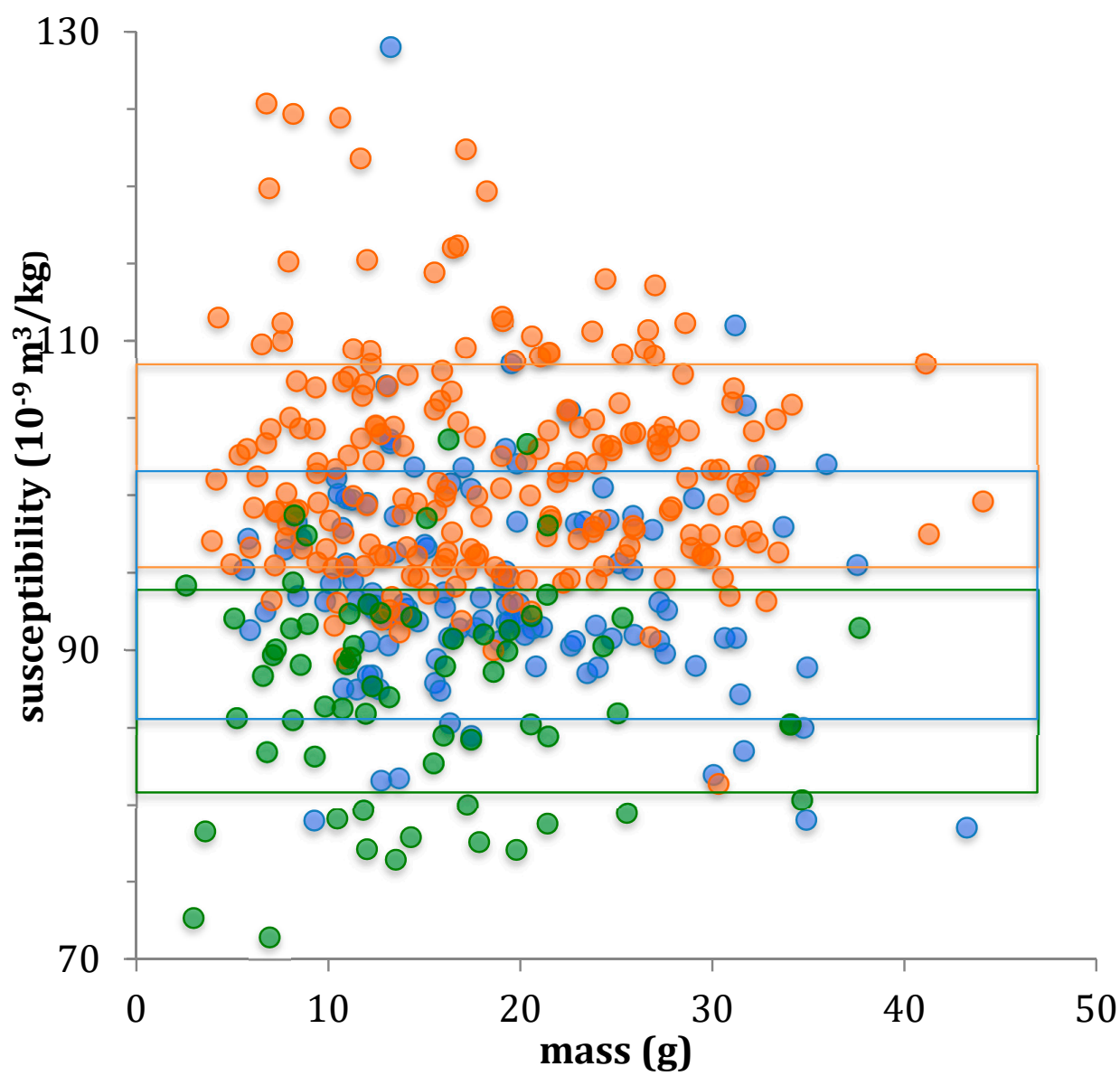

Figure 3. Magnetic susceptibility versus mass data obtained in Leyden australasite collection using SM150 instrument for three different geographic provenances: Indonesia (orange), the Philippines, and Vietnam (blue), other (rest of Indochina, Australia: green). Boxes correspond to average plus or minus one s.d, with the same color code as individual data.

Muong Nong layered tektites from the australasite strewn-field stands out by showing consistently higher $\mathrm{M}_{\mathrm{RS}}$ in the range 5-200 $\times 10^{-6} \mathrm{Am}^{2} / \mathrm{kg}$ [19] (our unpublished measurements on 8 samples). For samples with the highest remanence, ferromagnetic contribution to $\chi$ ought to be significant. Indeed, in our database, the sample with the highest $\mathrm{M}_{\mathrm{RS}}\left(116 \times 10^{-6} \mathrm{Am}^{2} / \mathrm{kg}\right)$ yields also the highest $\chi\left(107 \times 10^{-9} \mathrm{~m}^{3} / \mathrm{kg}\right)$. This sample produced a significant ferromagnetic signal after paramagnetic slope subtraction (Figure 4a). Magnetite amount, estimated from $\mathrm{M}_{\mathrm{S}}$, is about $20 \mathrm{ppm}$. Still, on average, Muong Nong tektites show $\chi$ values similar to other australasites (Table 1). Note that de Gasparis et al. [19] propose titanomagnetite as the carrier of remanence. Kleinmann [34] extracted magnetic spherules from crushed tektite from Indochina and the Philippines and found they were mostly made of magnetite.

Australasian microtektites may also be more magnetic than the standard tektites. Senftle et al. [17] report in microtektite samples with mass above $0.2 \mathrm{mg} \chi$ from 23 to $14710^{-9} \mathrm{~m}^{3} / \mathrm{kg}$ (note that we discarded the lower mass due to questionable reliability of the measurements). They also report $\mathrm{M}_{\mathrm{S}}$ up to $10^{-3} \mathrm{Am}^{2} / \mathrm{kg}$. This indicates significant amount of ferromagnetic impurities, as confirmed by our observation that a significant part of large microtektite from the South China Sea we studied in [35] are attracted by a magnet and present a dark color. 

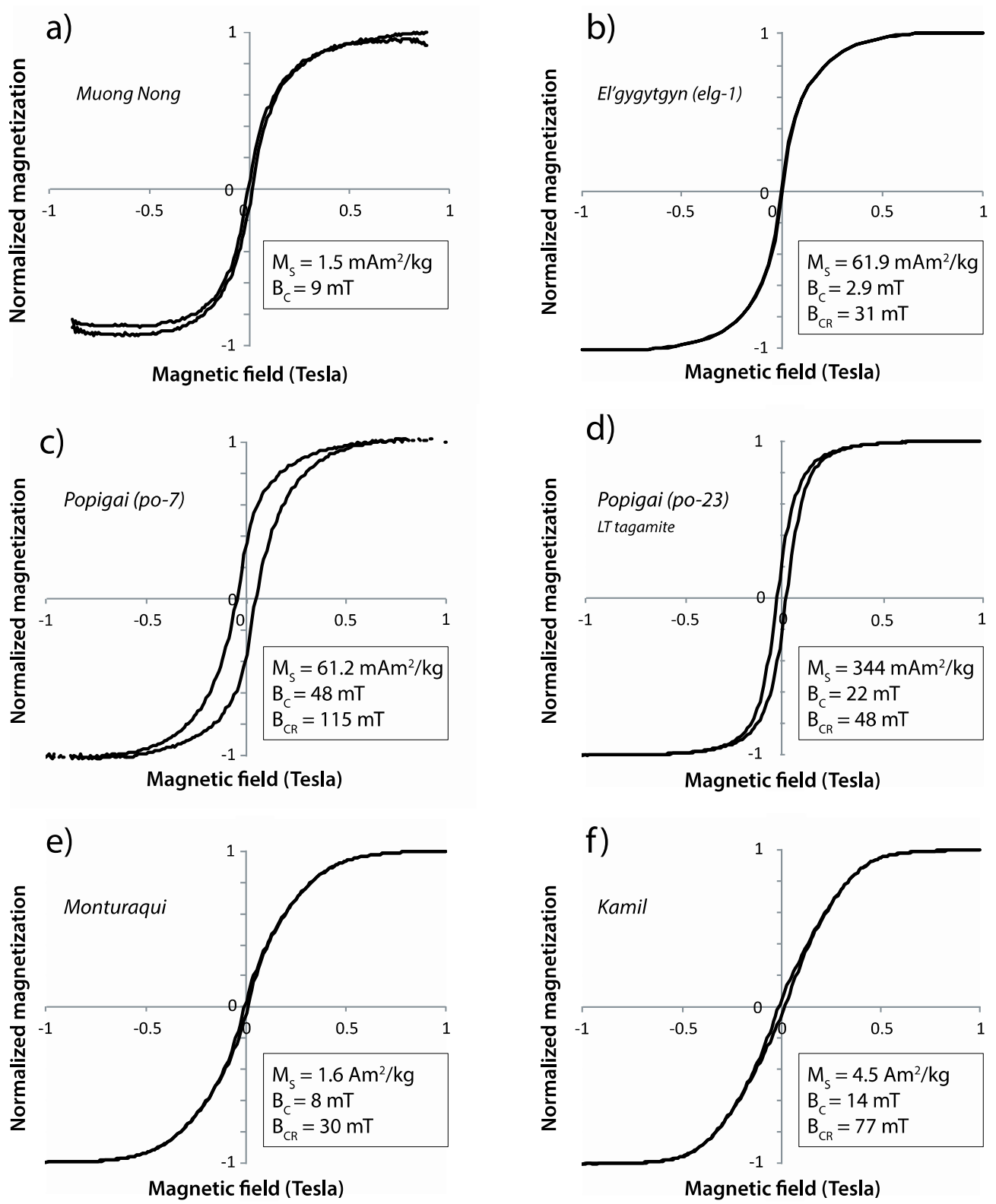

Figure 4. Examples of hysteresis loops, corrected for paramagnetism, obtained on impact glasses: (a) a titanomagnetite-rich Muong Nong tektite (note that strong paramagnetism prevented to obtain a well defined closed loop); (b) titanomagnetite-dominated El'gygytgyn glass; (c,d) pyrrhotite or magnetite-dominated Popigai glasses PO-7 and PO-23, respectively; (e,f) metal-bearing Monturaqui and Kamil glasses, respectively. LT tagamite is low-temperature tagamite (see Section 4.2.2).

\subsection{Magnetic Properties of Impact Glasses from Siberia}

\subsubsection{El'gygytgyn Impact Glasses}

El'gygytgyn impact crater is a $3.6 \mathrm{Ma}, 18 \mathrm{~km}$ diameter impact structure located in the central part of Chukotka peninsula and centered at $67^{\circ} 30^{\prime} \mathrm{N}$ and $172^{\circ} 05^{\prime} \mathrm{E}$ (e.g., [36]). Target rocks are rhyolitic to andesitic lavas. The crater depression is occupied by a lake having the same name. The El'gygytgyn impact bombs used in this study were collected in the southern and western sections of El'gygytgyn lake shore and from bed deposits of a stream falling into the lake. The bombs consist of translucent (in thin splits) homogeneous black $\mathrm{SiO}_{2}$-rich glasses without rock and mineral inclusions and are similar to the glasses described previously $[37,38]$. 
We investigated low-field susceptibility $\chi$ on subsamples with masses ranging from 0.3 to $18 \mathrm{~g}$. $\chi$ varies from 1231 to $2772 \times 10^{-9} \mathrm{~m}^{3} / \mathrm{kg}$ with similar mean values for the first two glass bombs and from 417 to $507 \times 10^{-9} \mathrm{~m}^{3} / \mathrm{kg}$ for the third glass bomb. The average $\chi$ values with standard deviation for each of three glass bombs are presented in Table 2.

Table 2. Main magnetic properties of impact glasses: new cases from Siberia. $\chi$ is low-field magnetic susceptibility; $\mathrm{Fd}$ is frequency dependence of $\chi_{;} \chi_{\mathrm{HF}}$ is high-field magnetic susceptibility; $\mathrm{M}_{\mathrm{S}}$ is saturation magnetization; $\mathrm{M}_{\mathrm{RS}}$ is saturation remnant magnetization; $\mathrm{B}_{\mathrm{C}}$ is coercivity, $\mathrm{B}_{\mathrm{CR}}$ is remanent coercivity; $\mathrm{N}$ is the number of sub-samples measured; for Popigai, only samples with hysteresis data are reported.

\begin{tabular}{|c|c|c|c|c|c|c|c|c|}
\hline Name (N) & $\begin{array}{l}\chi \times 10^{-9} \\
\left(\mathrm{~m}^{3} / \mathrm{kg}\right)\end{array}$ & $\begin{array}{l}\text { Fd } \\
(\%)\end{array}$ & $\begin{array}{c}\mathrm{M}_{\mathrm{S}} \times 10^{-3} \\
\left(\mathrm{Am}^{2} / \mathrm{kg}\right)\end{array}$ & $\mathbf{M}_{\mathrm{RS}} / \mathbf{M}_{\mathrm{S}}$ & $\begin{array}{c}B_{C} \\
(\mathrm{mT})\end{array}$ & $\begin{array}{c}\mathrm{B}_{\mathrm{CR}} \\
(\mathrm{mT})\end{array}$ & $\begin{array}{c}\chi_{\mathrm{HF}} \times 10^{-9} \\
\left(\mathrm{~m}^{3} / \mathrm{kg}\right)\end{array}$ & $\underset{(\%)}{\chi_{\mathrm{HF}} / \chi_{0}}$ \\
\hline \multicolumn{9}{|l|}{ Popigai Glasses } \\
\hline PO-4 & 170 & 5.8 & 3.6 & 0.330 & 30 & 65 & 128 & 60 \\
\hline PO-6 & 914 & 5.2 & 16.8 & 0.142 & 10 & 35 & 78 & 7 \\
\hline PO-7 & 335 & 5.1 & 61.2 & 0.350 & 48 & 115 & 141 & 33 \\
\hline PO-15 & 227 & 1.7 & 22.6 & 0.250 & 43 & 65 & 117 & 41 \\
\hline PO-22 & 270 & 2.0 & 361 & 0.177 & 13 & 29 & 72 & 21 \\
\hline PO-23 & 4970 & 2.6 & 344 & 0.226 & 22 & 48 & 125 & 2 \\
\hline PO-24 & 572 & 13.8 & 67.7 & 0.337 & 28 & 42 & 133 & 18 \\
\hline PO-27 & 381 & 2.1 & 79.2 & 0.317 & 29 & 48 & 137 & 29 \\
\hline PO-29 & 220 & 1.7 & 21.8 & 0.297 & 38 & 71 & 135 & 49 \\
\hline elg-3 (4) & $473 \pm 42$ & $6-7$ & 41.6 & 0.040 & 6.6 & 35 & 88 & - \\
\hline \multicolumn{9}{|l|}{ Uregoites } \\
\hline U-1 & 19.2 & 3 & - & - & - & - & - & - \\
\hline U-2 & 9.98 & - & - & - & - & 69.0 & - & - \\
\hline U-3 & 19.9 & - & 0.535 & 0.083 & 12.5 & 68.5 & - & - \\
\hline \multicolumn{9}{|l|}{ South-Ural Glass } \\
\hline A-1 & 4.7 & - & - & - & & - & - & - \\
\hline
\end{tabular}

The average $\chi$ for all El'gygytgyn glass samples is $(1622 \pm 924) \times 10^{-9} \mathrm{~m}^{3} / \mathrm{kg}(12$ samples from 3 glass bombs). Frequency dependence of $\chi$ is non-negligible and varies from 6 to $12 \%$, which may point out to the presence of superparamagnetic (i.e., nm-sized) grains.

We used smaller chips (0.3-0.5 g) to acquire hysteresis loops and backfield remanence demagnetization curves. All data are presented in Table 2 (an example in Figure $4 \mathrm{~b}$ ), and are typical for substituted magnetite of variable grain size, as observed using electron microscopy by [38]. Saturation magnetization values $\mathrm{M}_{\mathrm{S}}$ range from 42 to $80 \times 10^{-3} \mathrm{Am}^{2} / \mathrm{kg}$ pointing to the presence of a non-negligible ferrimagnetic contribution ( $1 \%$ range).

\subsubsection{Popigai Impact Glasses}

Popigai impact structure is located in Siberia, Russia (northern margin of the Anabar shield, $71^{\circ} 38^{\prime}$ $\mathrm{N} 111^{\circ} 11^{\prime} \mathrm{E}$ ): its diameter is $\sim 100 \mathrm{~km}$ and estimated age $35.7 \pm 0.2 \mathrm{Ma}[36,39]$. Its melt sheet exceeds several $\mathrm{km}$ in thickness. We investigated 27 samples of Popigai impact melt rocks (tagamites) from 15 different boreholes and impact glasses from a variety of glass bombs from surface outcrops (sample collection from VSEGEI, Russia, provided by V.L. Masaitis). The $5-15 \mathrm{~cm}$ glass bombs were taken from suevite outcrops. Tagamite samples were collected from depths of 21-981 m. Geochemistry and petrology of the samples is described in $[39,40]$.

Magnetic susceptibility $\chi$ was measured for all 27 samples with masses ranging from 3.5 to $13.9 \mathrm{~g}$. If we exclude one clear outlier (PO-23, see Table 2), $\chi$ ranges from 104 to 914 with the average $\chi=(248 \pm 165) \times 10^{-9} \mathrm{~m}^{3} / \mathrm{kg}$. Some of these data are presented in Table 2 . 
We used smaller chips to measure hysteresis loops and backfield remanence demagnetization curves (Table 2). Saturation magnetization $\mathrm{M}_{S}$ of the samples varies from 3.6 to $361 \times 10^{-3} \mathrm{Am}^{2} / \mathrm{kg}$, which indicates up to a few wt \%o of ferrimagnetic minerals. Hysteresis points toward two types of magnetic minerals: one hard (Figure $4 \mathrm{c}$ ) and one soft (Figure $4 \mathrm{~d}$ ), with $\mathrm{S}$ ratio (remanence at $0.3 \mathrm{~T}$ divided by remanence at $1 \mathrm{~T}$ ) down to 0.67 and $>0.95$, respectively. Significant frequency dependence, up to $14 \%$, may be observed in both behaviors although the majority of samples have $\mathrm{fd} \%<3$.

It is tempting to identify these two phases as magnetite and pyrrhotite, respectively. Indeed, pyrrhotite was previously reported in Popigai impact glasses [39,40]: low-temperature (LT) tagamites were reported to have single domain and multidomain pyrrhotite grains, whereas high-temperature (HT) tagamites were reported to have superparamagnetic pyrrhotite grains [39]. In this study, PO-23 is LT tagamite, PO-24 is HT tagamite [39].

To confirm this identification, we studied further two extreme cases, PO-7 and PO-23, respectively hard and soft, with large $\mathrm{M}_{\mathrm{S}}$. Both contain sulfides visible under the binocular microscope, with blebs up to $1 \mathrm{~mm}$ in the case of PO-23. A magnetic extract performed on gently crushed PO-23 confirms that the sulfides are magnetic, and are thus likely pyrrhotite. However, low-field magnetic susceptibility versus temperature measurements on both samples reveal only a minor or hardly visible (PO-7 case) Curie temperature of monoclinic pyrrhotite $\left(\sim 320^{\circ} \mathrm{C}\right)$ (Figure $\left.5 \mathrm{a}, \mathrm{c}\right)$.
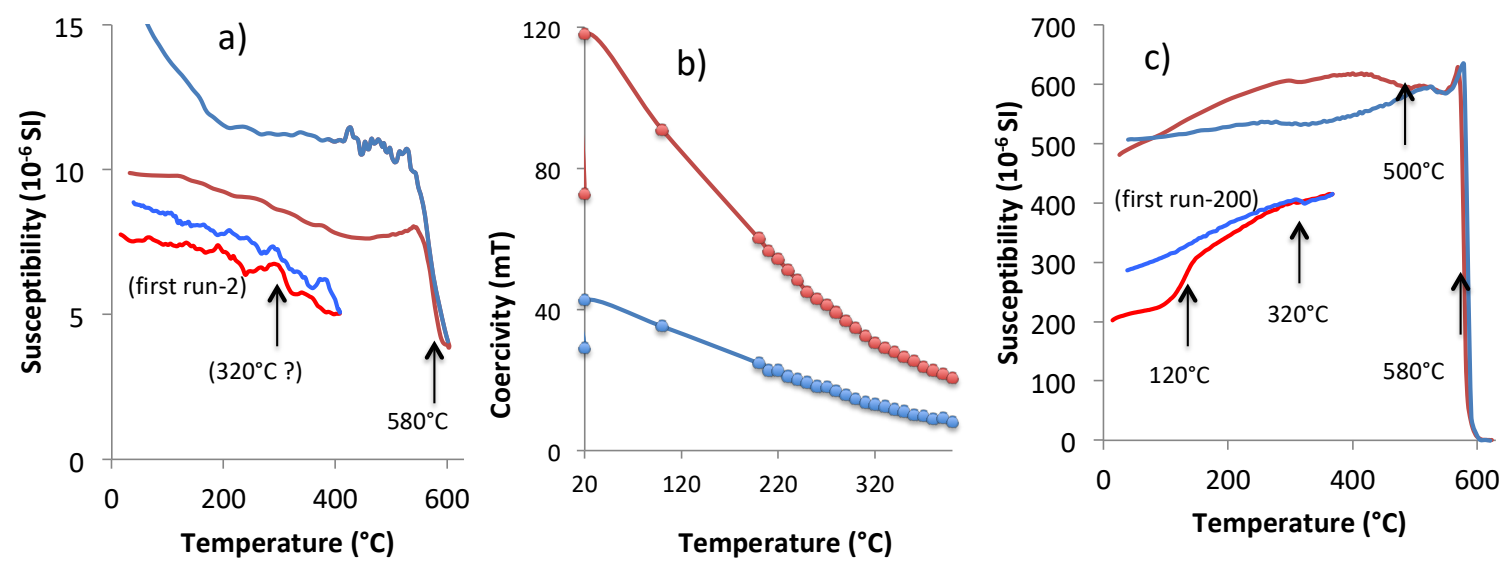

Figure 5. High temperature data for Popigai glasses: (a) sample PO-7 susceptibility versus temperature; (b) sample PO-7, $\mathrm{B}_{\mathrm{CR}}$ (red), $\mathrm{B}_{\mathrm{C}}$ (blue) as a function of temperature during heating; second lower value at room temperature (RT) corresponds to remeasure after heating circle; (c) sample PO-23 susceptibility versus temperature. Heating and cooling curves in a) and (c) are indicated in red and blue, respectively.

This is particularly surprising for the PO-7 case, which exhibits a pure fine-grained pyrrhotite-like hysteresis. Hysteresis at variable temperature up to $400{ }^{\circ} \mathrm{C}$ for PO-7 (Figure 5b) shows that the high coercivity signal promptly disappear with hardy visible discontinuity around $320^{\circ} \mathrm{C}$. Cooling from $400{ }^{\circ} \mathrm{C}$ results in a soft behavior at room temperature, suggesting that the magnetically hard behavior is due to a metastable phase or defects disappearing on annealing, as proposed for martian meteorites [41]. On the other hand, another high coercivity sample (PO-9) does show a significant inflexion near $330{ }^{\circ} \mathrm{C}$ on coercivity and $\mathrm{M}_{\mathrm{RS}} / \mathrm{M}_{\mathrm{S}}$ values. Low temperature remanence curves (Figure 6) show in some samples low amplitude expression of the pyrrhotite (i.e., Besnus transition, better expressed in PO-9) and pure magnetite (i.e., Verwey transition). The magnetic mineralogy of Popigai glasses is obviously complex (see Figure $5 b$ with a suggestion of up to four different phase transitions) and deserves further dedicated investigations. 


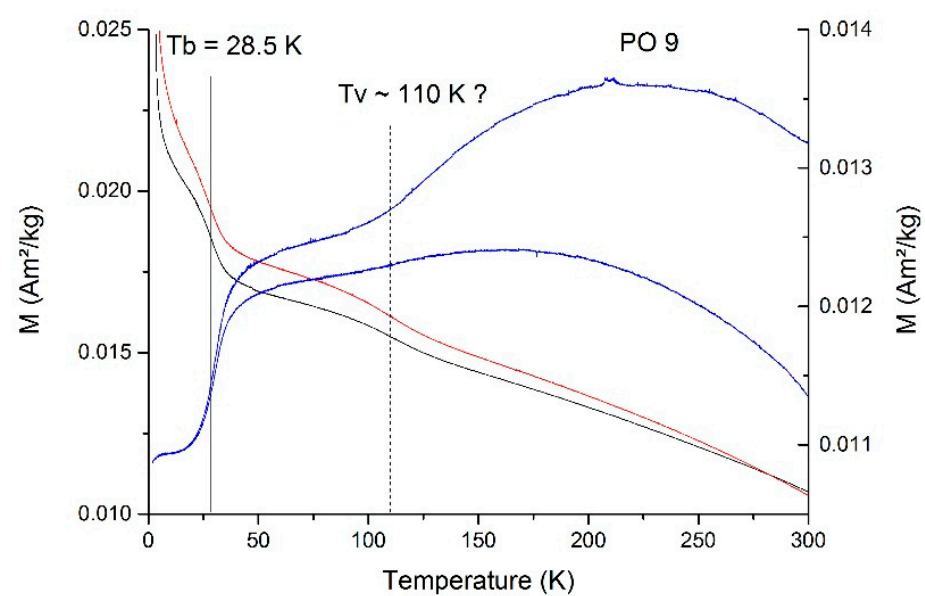

(a)

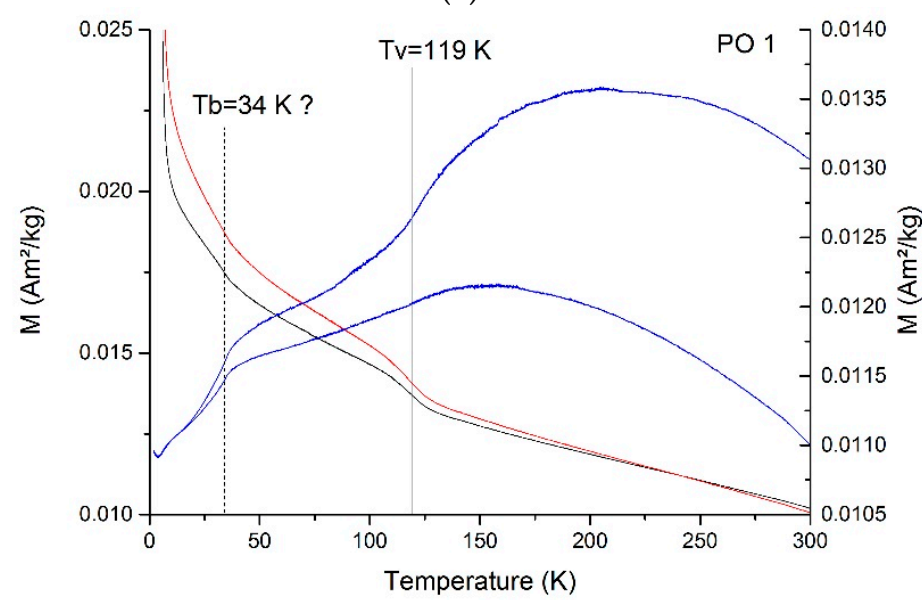

(b)

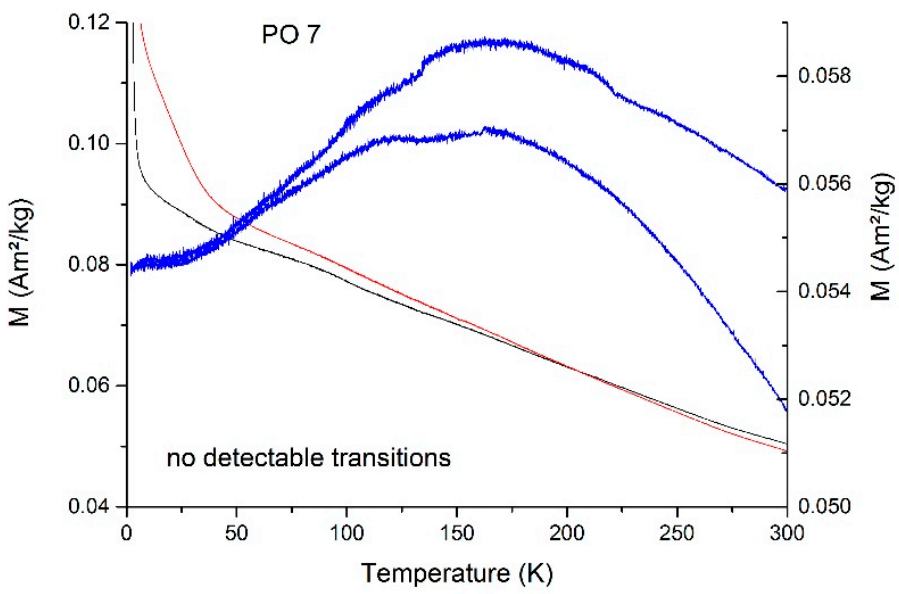

(c)

Figure 6. (a-c) Low-temperature properties of Popigai samples PO9, PO1, PO7. ZFC curves are shown in black, FC in red, room temperature SIRM cycle to $1.8 \mathrm{~K}$ in blue. ZFC and FC curves are shown above $10 \mathrm{~K}$ to emphasize Besnus and Verwey phase transitions. (a) and (b) show the samples with both Verwey and Besnus transitions, in variable proportion, (c) shows a sample with no detectable transitions. Where appropriate, transition temperatures are marked by vertical lines.

\subsubsection{Urengoites}

Masaitis et al. [42] reported the finding of three glass pebbles (U1 to U3) in fluvioglacial sand deposits, separated by a $40 \mathrm{~km}$ distance near Novi Urengoï in West Siberia $\left(66^{\circ} \mathrm{N}, 78^{\circ} \mathrm{E}\right)$. Their size 
varies from 1 to $3 \mathrm{~cm}$, with light green color. Their composition is $\mathrm{SiO}_{2}$-rich (89.4 to $95.2 \mathrm{wt} \%$ ), with $\mathrm{FeO}$ from 0.32 to $1.03 \mathrm{wt} \%$ [13]. They show fluidal texture and lechatelierite-like inclusions (Figure 7), as well as very low water content, from 80 to $240 \mathrm{ppm}$ [43], both suggestive of tektite-like impact glass.

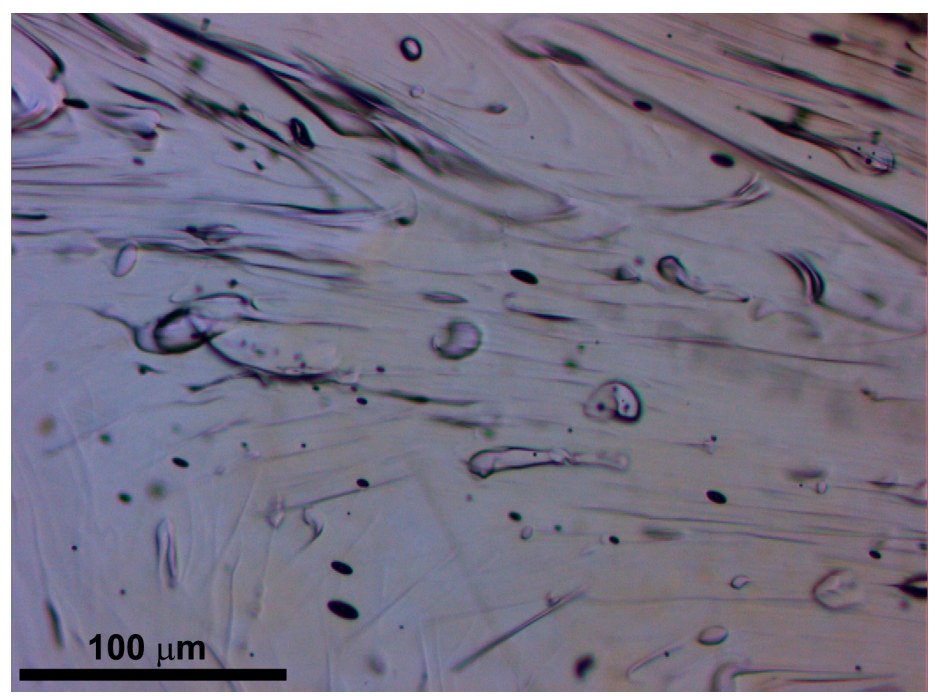

Figure 7. Transmission optical image of urengoite U1.

Masaitis et al. [42] reported Mössbauer spectroscopy (MS) data compatible with the lack of $\mathrm{Fe}^{3+}$. As MS data may be ambiguous to allow discussion of the oxidation state of iron [44], we undertook $X$-ray spectroscopic investigations at the Fe edge of U1 sample (the richest in iron). The Fe K-edge XANES spectrum of the urengoite sample is shown in Figure 8, whereas the background subtracted pre-edge peak (labeled $P$ in the XANES spectrum) is shown in the inset.

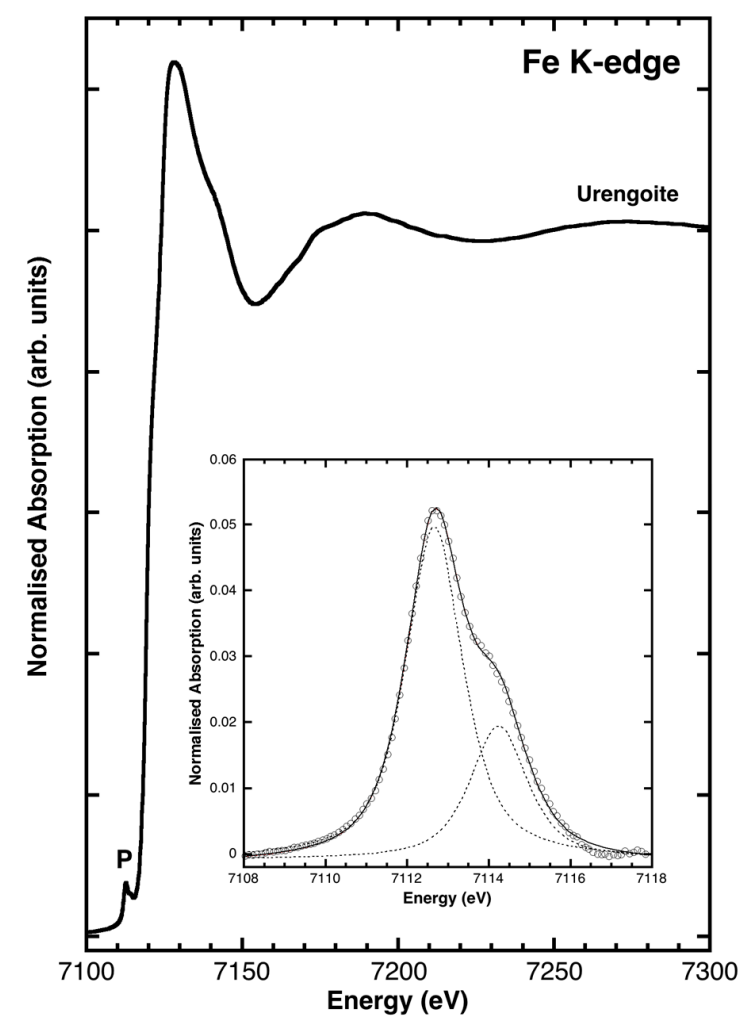

Figure 8. Fe K-edge XANES spectra of urengoite U1; background subtracted pre-edge peak (labeled P in the XANES spectrum) shown in the inset. 
The spectrum displays only broad features, compatible with the glassy nature of the sample. The edge energy, as determined by the maximum in the first derivative spectrum, is located at $7119.2 \mathrm{eV}$, compatible with the presence of divalent iron. The general shape of the spectrum is very similar to that of tektites from the Australasian, Central European, Ivory Coast, and North American strewn fields (see $[27,29,30])$. The background-subtracted pre-edge peak has been fitted with two pseudoVoigt functions constrained to have the same full width at half maximum (FWHM) and Lorentian degree, resulting in a centroid energy of 7113.08 and an integrated intensity of 0.136 . Comparison of pre-edge peak data with those of Fe model compounds allow to determine $\mathrm{Fe}^{3+} /\left(\mathrm{Fe}^{2+}+\mathrm{Fe}^{3+}\right)=0.06 \pm 0.05$ and an average $\mathrm{Fe}^{2+}$ coordination number intermediate between [4] and [5]. All the XAS data measured are compatible with those of tektite and Darwin glass reported in the literature so far (Figure 9), and distinct from other glasses such as irghizites and LDG.

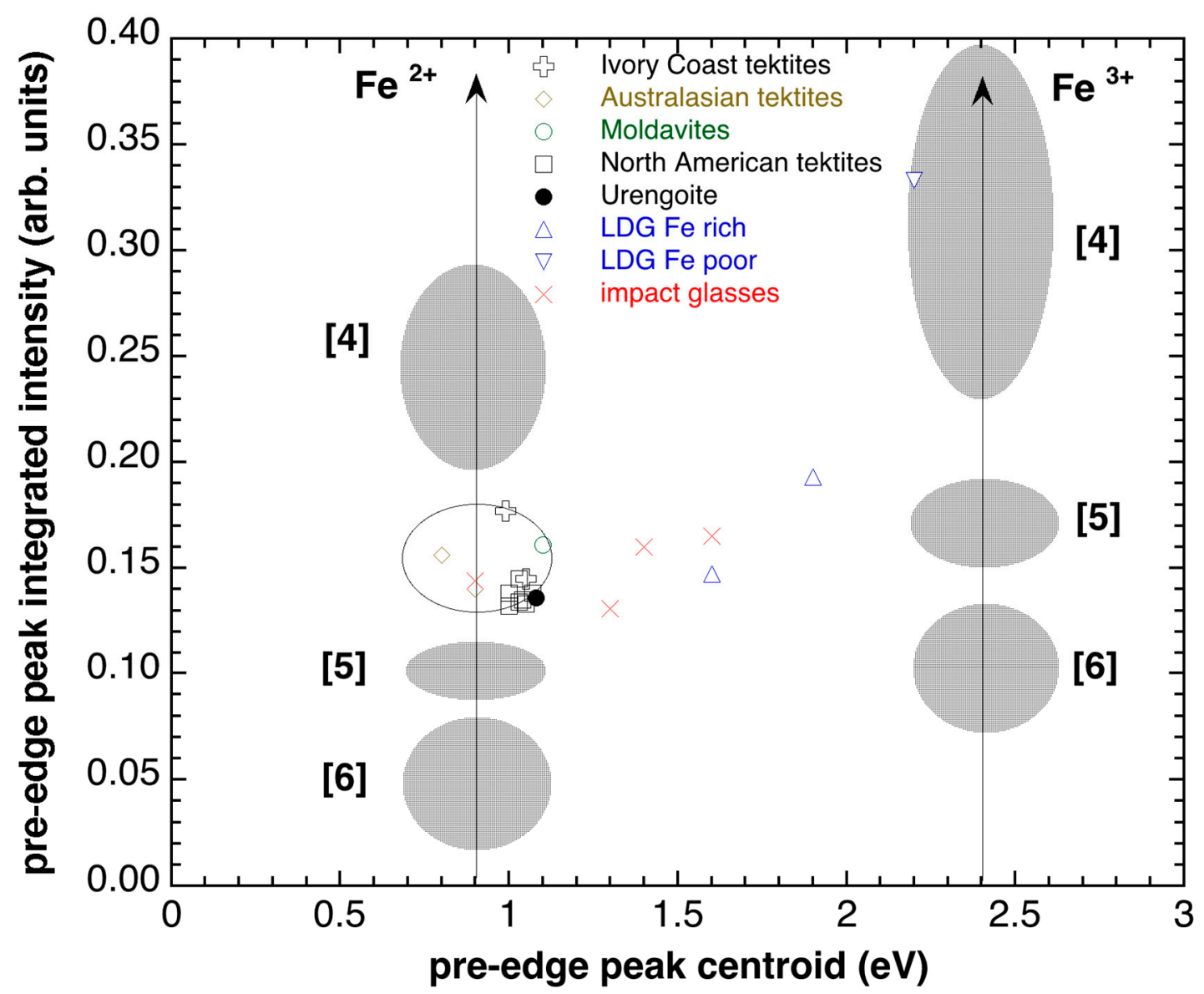

Figure 9. Fe-K-edge pre-edge peak data for urengoite compared to tektites, Darwin glass, LDG, and irghizite (after $[27,29,30,45]$. All the tektites fall in a narrow range of centroid energies and pre-edge peak integrated area, which indicates the presence of $\mathrm{Fe}^{2+}$ with average coordination numbers intermediate between 4 and 5. On the other hand, impact glasses span a wide range of Fe oxidation state from dominantly divalent (like in Wabar glasses) to dominantly trivalent (like in Fe-poor Libyan desert glass).

Magnetic susceptibility as well as $\mathrm{M}_{\mathrm{RS}}$ are very low: 10 to $20 \times 10^{-9} \mathrm{~m}^{3} / \mathrm{kg}$ and 4 (U1) to 62 (U3) $10^{-6} \mathrm{Am}^{2} / \mathrm{kg}$, respectively (Table 2). For U1 the magnetic susceptibility appears dominated by paramagnetism (Figure 2 inset), while U3 (and to a lesser extent U2) shows a significant ferromagnetic signal (Figure 10a). Low temperature SIRM warming curve (Figure 10b) shows a strong continual decrease typical of superparamagnetic grains. A slight hint of the Verwey transition around $\sim 120 \mathrm{~K}$ is seen on the magnetization derivative (Figure 10c), indicating some magnetite. $\mathrm{M}_{\mathrm{S}}$ value corresponds to 6 ppm of magnetite, i.e., of the order of Muong Nong magnetite content. 


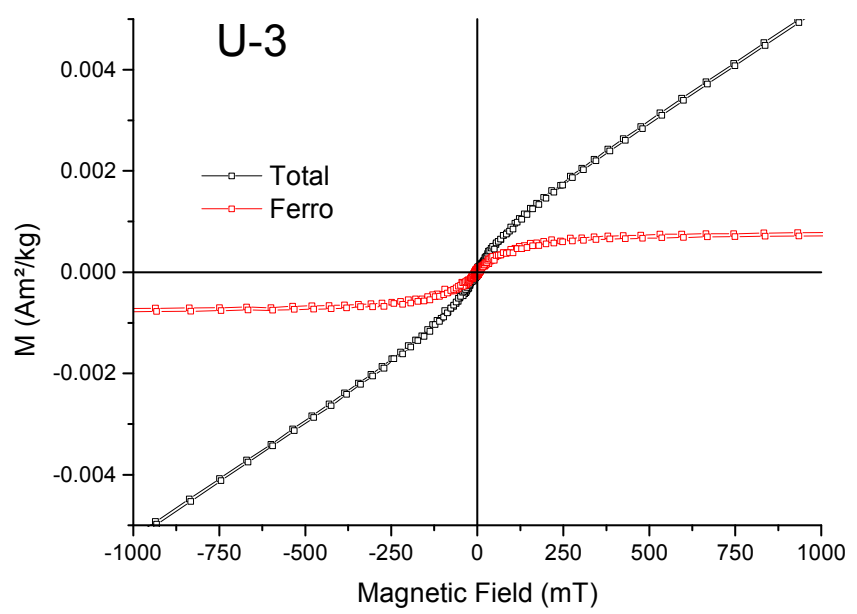

(a)

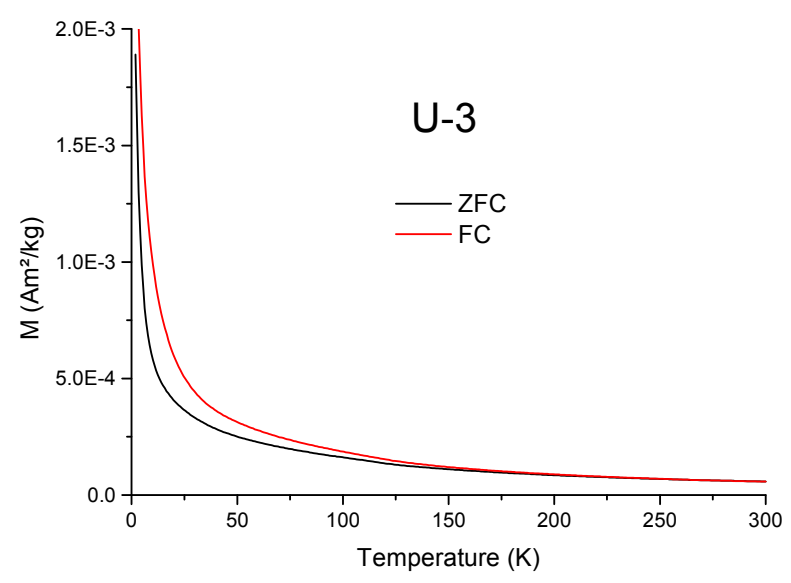

(b)

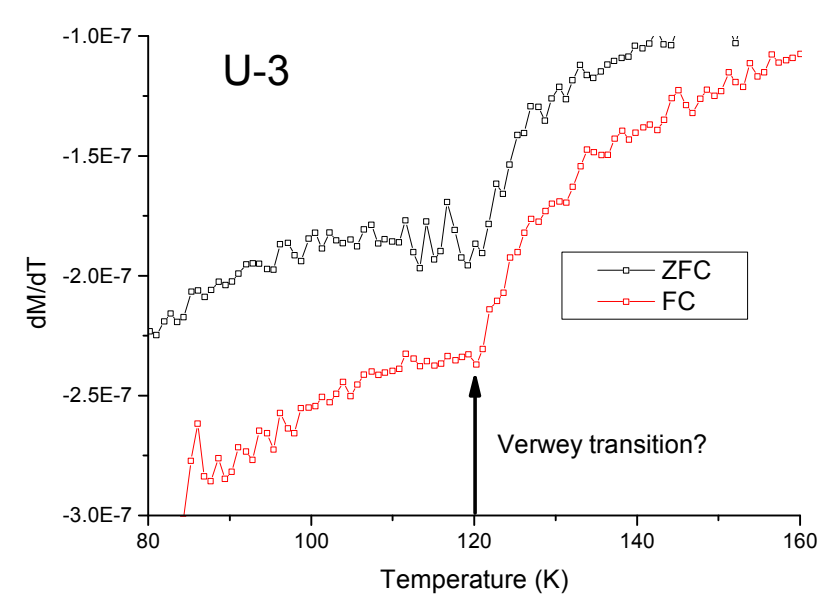

(c)

Figure 10. (a) Room temperature hysteresis for urengoite U3; (b) low-temperature remanence heating curves; (c) remanence derivative from $(\mathbf{b})$ showing probable Verwey transition of magnetite.

Urengoites, dated around $24 \mathrm{Ma}$ by fission tracks and $\mathrm{K} / \mathrm{Ar}$ [13], share a number of characteristics of tektites: fluidal glass with low vesicularity and no other inclusions than lechatelierite, very low water content, reduced nature, and very low ferromagnetic content. However, some features indicate 
they are not typical tektites, in particular the chemical and isotopic heterogeneity [13]. Together with the variable ferromagnetic content observed (up to $6 \mathrm{ppm}$ ), we propose that the closest analogs to urengoites are either Muong Nong tektites or Darwin glass.

\subsubsection{South-Ural Glass}

A single light green glass pebble weighing $90 \mathrm{~g}$ was found in eluvial-dealluvial placer at the Astaf'evskoe piezoquartz deposit $75 \mathrm{~km}$ east of Magnitogorsk ( $\left.53^{\circ} 37^{\prime} \mathrm{N}, 60^{\circ} 10^{\prime} \mathrm{E}\right)$ and first studied in [46]. Deutsch et al. [13] report amounts of $\mathrm{SiO}_{2}$ of $66.9 \mathrm{wt} \%$ and $\mathrm{FeO}$ of $0.43 \mathrm{wt} \%$, as well as lack of $\mathrm{Fe}^{3+}$ based on Mössbauer spectroscopy. On the other hand, electron spin resonance indicated minor but detectable $\mathrm{Fe}^{3+}$ [46]. Our microscopic investigations reveal no sign of fluidality (contrary to [46]) and no inclusions in this very homogeneous glass. We measured with FTIR a water content of $414 \mathrm{ppm}$, higher than all impact glasses except LDG [43]. Magnetic measurements on a $3.7 \mathrm{~g}$ sample yield a susceptibility of $4.7 \times 10^{-9} \mathrm{~m}^{3} / \mathrm{kg}$ and $\mathrm{M}_{\mathrm{RS}}$ of $6-9 \times 10^{-6} \mathrm{Am}^{2} / \mathrm{kg}$ (2 samples). Susceptibility is compatible with pure paramagnetism (Figure 2 inset). A SIRM warming curve reveals a pronounced superparamagnetic or spin glass behavior, typical of nanometric clusters of iron, with no Verwey transition (Figure 11).

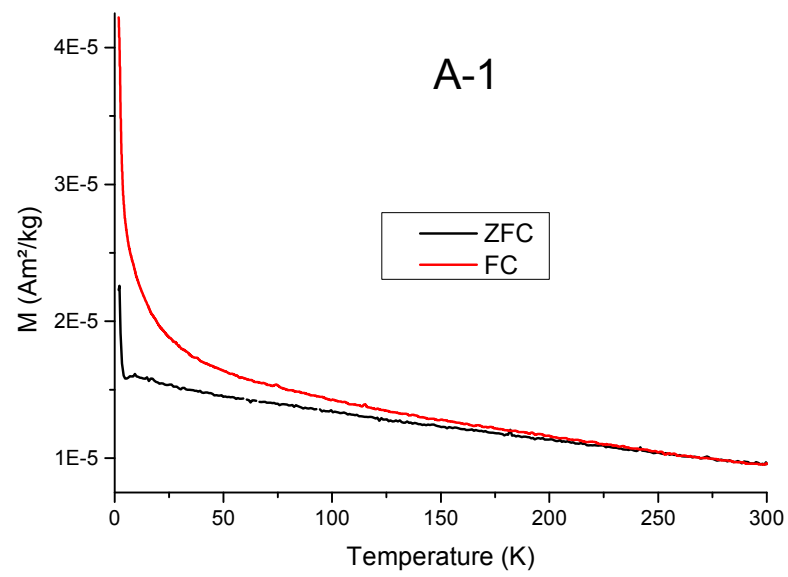

(a)

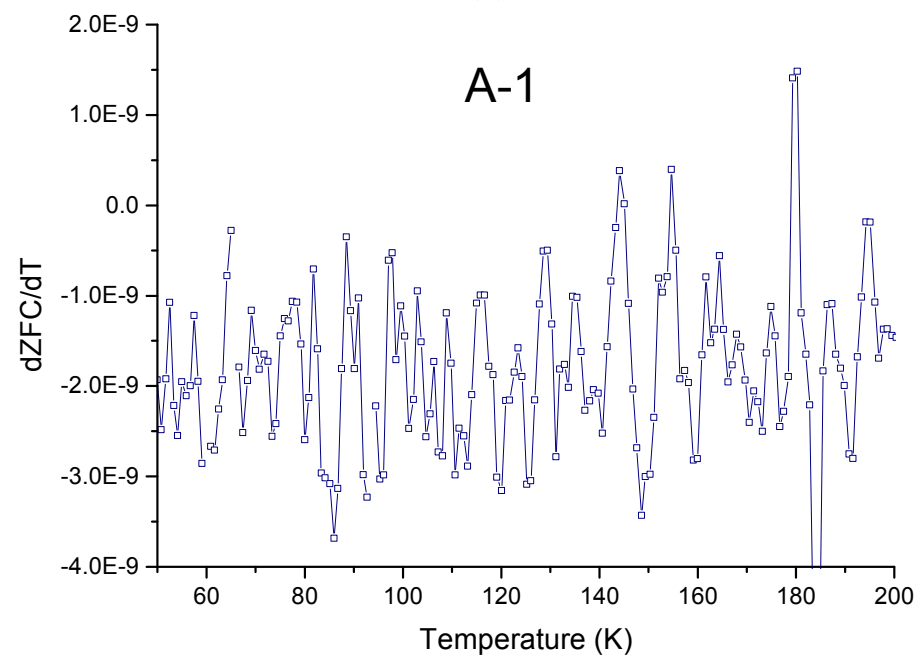

(b)

Figure 11. (a) Low temperature remanence data for South-Ural glass; (b) remanence derivative from a) showing lack of transition. 
Microprobe data show that chemical composition is homogeneous but anomalous for tektites regarding the high $\mathrm{CaO}$ content $(12.1 \mathrm{wt} \%)$ and non-zero $\mathrm{P}_{2} \mathrm{O}_{5}(0.19 \mathrm{wt} \%)$. Moreover, the fluorine content is as high as $3.5 \mathrm{wt} \%$ that is unusual for natural glasses. Together with other characteristics (lack of inclusions and fluidality, water content), this suggests that South-Ural glass may be a man-made glass, rounded in the surface for some decades. Indeed, the region of Magnitogorsk (and more general South-Ural) was a site on intense heavy industry during the Soviet Union period since 1930, leading to spill of numerous by-products of metal and glass production or other high-temperature processes. It is nowadays among the most polluted sites in Russia. This makes the casual finding of manufactured glass rounded in surface gravels not an impossible event. Note that in the urengoite case, at the Novy Urengoi area, the only industry is natural gas extraction that started in 1975.

The K/Ar age of $6.2 \pm 0.3$ Ma obtained on this glass [46] sounds contradictory with a man-made origin. However, it is possible that during the manufacture of this glass starting from old geological material, the ${ }^{40} \mathrm{Ar}$ initially present was not fully degassed.

\subsection{Overview of Impact Glasses with Variable Ferromagnetic Content}

Apart from Darwin glass and urengoites (neglecting the 6 ppm magnetite content of U3), all other studied non tektite glasses appear to have variable but often significant ferromagnetic contributions, as demonstrated in [9] on irghizite, atacamaite, Aouelloul, Wabar, and Libyan desert glasses (LDG). This general behavior is due to the fact that a significant part of total iron is in $\mathrm{Fe}^{3+}$ form in these glasses with an average oxidation state of up to 3 for LDG and 2.8 for zamanshinite $[27,45,47]$. These studies also show that, within a strewn field, average oxidation may be quite variable. On the other hand, one may find metallic iron spherules due to impactor contamination $[48,49]$. The present synthesis will build on the two new Siberian impact glasses studied above, previous synthesis [9] as well as magnetic studies on Lappajärvi crater melt rocks [50], Lonar crater glass [51,52], of Mistastin crater melt rocks [53], of Jänisjärvi crater melt rocks [10], of Pantasma crater glass [11], complemented with $\mathrm{M}_{\mathrm{RS}}$ data from [20]. Data from [12] on irghizites will also be used to complement the database [9]. New magnetic data on glasses from Lonar, Ries, Kamil, Monturaqui, Lappajärvi, and Henbury craters have also been acquired for this study. Among the 16 cases reviewed in this chapter (see Table 3), two are glass strewn-fields of a few tens of km extension without known source craters: LDG and atacamaite.

While the first is yet enigmatic (e.g., LDG have been proposed to be the result of an airburst rather than a crater [54]), the strong analogy between atacamaite and irghizite (both resembling miniature splash-form tektites, thus the term tektoid coined by Rochette et al. [9]) suggest a proximal impact crater for atacamaite. In the remaining cases, 4 come from impact melt sheets found within the crater (Jänisjärvi, Lappajärvi, Mistastin, Popigai cases) while the 10 others are clearly proximal ejecta. We point out that the melt sheets studied here are often not real glass but cryptocrystalline material with minor devitrified glass, although real glass may dominate in Mistastin and Popigai.

The magnetic susceptibitility of these glasses or rocks may, for some samples, be strongly dominated by paramagnetism (case of Aouelloul glass, irghizite, and atacamaite [9]) but a significant to major part of the samples is dominated by variable ferromagnetism. This results in a large spread of susceptibility (highlighted by coefficient of variation much higher than $30 \%$, see distribution in Figure 12 compared to the tektite cases) and $\mathrm{M}_{\mathrm{S}}$ or $\mathrm{M}_{\mathrm{RS}}$ values (up to 4 orders of magnitude for $\mathrm{M}_{\mathrm{RS}}$ of atacamaites). A frequent characteristic of these glasses is also large frequency dependence of susceptibility (Table 3), indicative of the abundance of superparamagnetic (SP) grains (grain size below about $20 \mathrm{~nm}$ ). This abundance is confirmed by the hysteresis parameters and viscosity tests (e.g., Figures 5 and 6 in [9]); in the case of irghizite, liquid helium temperature remanence warming curves also indicated abundant SP grains [12]. Note that low $\mathrm{fd} \%$ may either be due to the lack of SP particles or to a predominance of paramagnetic contribution in susceptibility. 
Table 3. Synthesis on magnetic properties of non paramagnetic impact glasses, after [9] complemented with data from $[10-12,20,50,52,53]$ and this work. Sites are ordered by increasing mean susceptibility, with impact melt sheets at the end. When known the diameter in $\mathrm{km}$ of the source crater is indicated within brackets. $\mathrm{N}$ is the number of data used for mean susceptibility, and $\mathrm{CF}$ its coefficient of variation. $\mathrm{Fd} \%, \mathrm{M}_{\mathrm{S}}$, and $\mathrm{M}_{\mathrm{RS}}$ may rely on less samples.

\begin{tabular}{|c|c|c|c|c|c|c|c|}
\hline Glass & $\begin{array}{c}\text { Mean } \chi \\
\left(10^{-9} \mathrm{~m}^{3} / \mathrm{kg}\right)\end{array}$ & CF (\%) & Range & $\mathbf{N}$ & $\mathbf{F d} \%$ & $\begin{array}{l}\mathrm{M}_{S}\left(10^{-3}\right. \\
\left.\mathrm{Am}^{2} / \mathbf{k g}\right)\end{array}$ & $\begin{array}{c}\mathrm{M}_{\mathrm{RS}}\left(\mathbf{1 0}^{-3}\right. \\
\left.\mathrm{Am}^{2} / \mathrm{kg}\right)\end{array}$ \\
\hline LDG (?) normal & -2.3 & 39 & -3.3 to -0.6 & 10 & & & \\
\hline LDG (?) dark & 4.4 & 71 & -0.1 to 10.8 & 8 & 11 & & 0.01 \\
\hline Aouelloul (0.4) & 82 & 89 & 38 to 463 & 65 & 14 & $0.3-19.6$ & $0.04-2.9$ \\
\hline Irghizite (6-14) & 167 & 126 & 45 to 3320 & 835 & 3 to 20 & 1 to 278 & 0.006 to 23 \\
\hline Wabar (0.1) & 468 & 58 & 125 to 1025 & 14 & 20 & 12 & 1.9 \\
\hline Atacamaite (?) & 302 & 286 & 84 to 20500 & 3291 & 7 to 16 & $0.4-2350$ & $0.02-280$ \\
\hline Ries (24) & 417 & 44 & 262 to 685 & 6 & 7 to 10 & & 1.5 \\
\hline El'gygytgyn (18) & 1712 & 90 & 180 to 4459 & 7 & 6 to 12 & 42 to 80 & 2.1 to 2.4 \\
\hline Henbury (0.2) & 3316 & 36 & 2190 to 4550 & 3 & & & 5 to 20 \\
\hline Lonar (1.8) & 5100 & 61 & 288 to 9705 & 20 & 2.5 to 4.5 & 8.2 to 1290 & 0.3 to 558 \\
\hline Kamil (0.05) & 8710 & 141 & 146 to 26100 & 7 & 3 to 11 & 18 to 4511 & 5 to 225 \\
\hline Monturaqui (0.5) & 12000 & 30 & 7600 to 17200 & 10 & 2 & 67 to 1629 & 3 to 65 \\
\hline $\begin{array}{l}\text { Pantasma (14) } \\
\text { Melt sheets }\end{array}$ & 13600 & 72 & 370 to 25600 & 3 & 3 to 23 & 26 to 926 & 5.5 to 111 \\
\hline Lappajärvi (23) & 277 & 20 & 210 to 420 & 23 & 1.4 & 80 to 230 & 34 to 58 \\
\hline Popigai (90) & 427 & 212 & 90 to 4965 & 28 & 0 to 14 & 4 to 361 & 1 to 78 \\
\hline Jänisjärvi (17) & 1978 & 82 & 74 to 2769 & 29 & & 1.9 to 184 & 0.06 to 33 \\
\hline Mistastin (28) & 3390 & 53 & $580-8400$ & 115 & & 65 to 1460 & 12 to 400 \\
\hline
\end{tabular}

Magnetic mineralogy of these impact glasses is dominated by substituted magnetite [9-12,51], as expected by their generally oxidized nature indicated for example by XANES (for LDG, Aouelloul, irghizite, Wabar; [27,45]) or Mössbauer spectroscopy studies (for Aouelloul, irghizite, Wabar; [44]). Substitution in magnetite is revealed by the spread of Curie or remanence unblocking temperatures well below $580^{\circ} \mathrm{C}$, as well as the lack or subdued character of the Verwey transition $[10,12,53]$. Besides the very fine-grained magnetite inclusions, one may encounter large oxide inclusions, likely derived from the melting of large iron oxides grains present within the target. In that case, microanalysis is possible, showing that the substituted elements are not what is usually observed in volcanic rocks. In the Pantasma glass case, substitution varied between 0.14 to 0.71 and average formula was: $\mathrm{Fe}_{2.5} \mathrm{Ti}_{0.28} \mathrm{Al}_{0.09} \mathrm{Mg}_{0.06} \mathrm{Mn}_{0.05} \mathrm{~V}_{0.01} \mathrm{O}_{4}$. The corresponding Curie points were spreaded up to $510{ }^{\circ} \mathrm{C}$. A peculiar morphology, named granular magnetite by Rochette et al. [11], has been encountered in these large grains from Pantasma, El'gygytgyn, and irghizite glasses (Figure 13). It is reminiscent of a two immiscible liquids texture, or of granular zircon found in impact glass [55]. This morphology may be typical of impact melts generated from target bearing large oxide grains, but this generalization needs further investigation. We note that some of the target rocks of these three craters are similar: andesitic to rhyolitic lavas [11,36]. Lavas are the only target rocks for Pantasma and El'gygytgyn while sedimentary target rocks dominate over lavas in Zhamanshin.

Other magnetic minerals are sometimes encountered, usually together with magnetite: hematite in the case of irghizite [9]; metal in the case of Aouelloul, Henbury, Wabar, Kamil, and Monturaqui glass [48,49,56,57]; pyrrhotite in the case of Lappäjarvi and Popigai glass. Metal and pyrrhotite occur usually as spherical droplets, indicative of immiscible liquid state. The discrimination between these different minerals may be performed at room temperature using hysteresis loops (Figure 4) and back-field curves, although the fact that more than one mineral may coexist makes the interpretation more complex. Metal seems more often encountered in rather small craters (see diameters in Table 3), and pyrrhotite in melt sheets within large craters. 


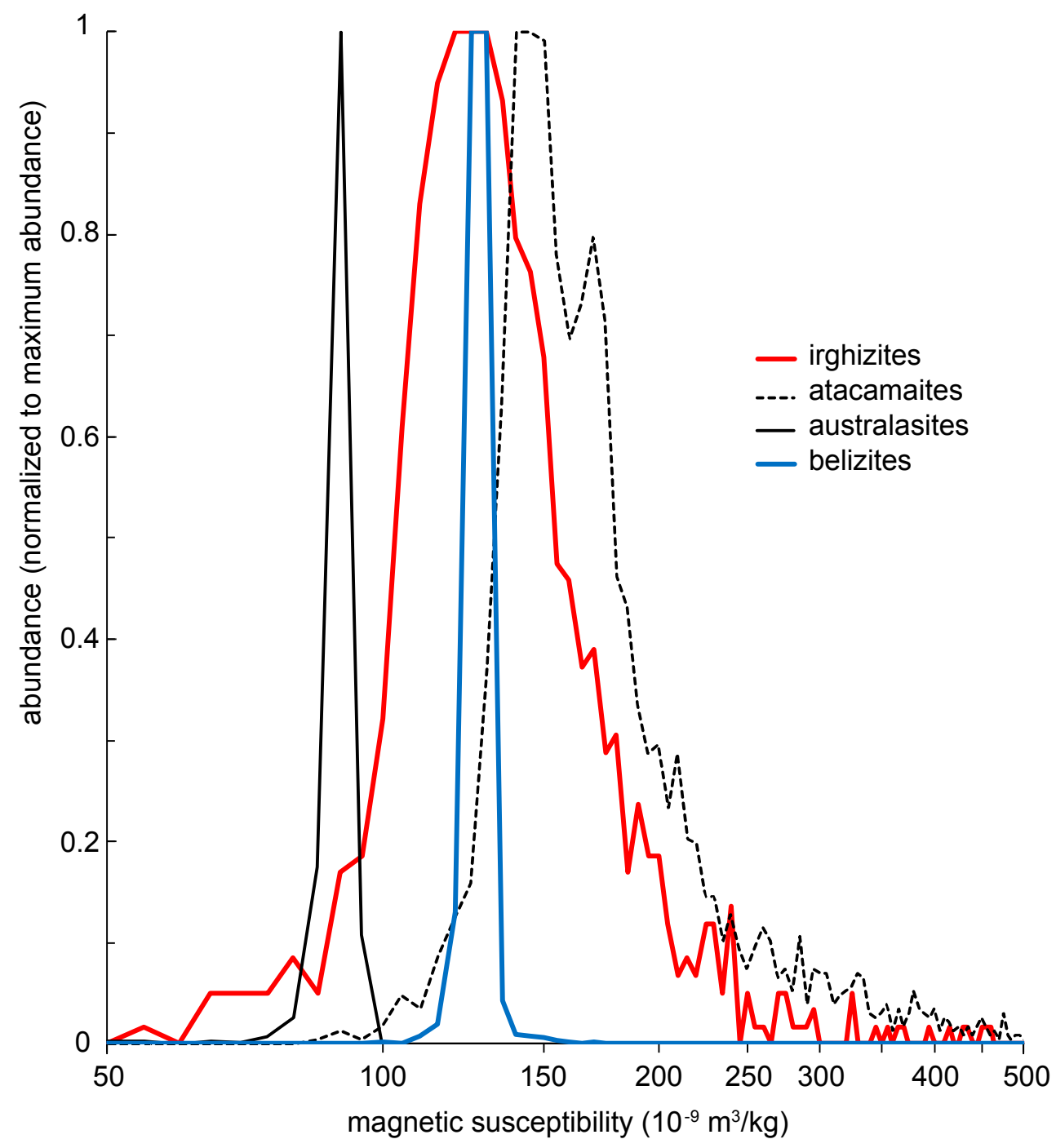

Figure 12. Distribution of magnetic susceptibility for studied impact glasses with more than 600 samples measured (see Tables 1 and 3; australasite data is from the S China dataset) showing the different dispersion between tektites and partly ferromagnetic impact glass. Bin used is $5 \times 10^{-9} \mathrm{~m}^{3} / \mathrm{kg}$.

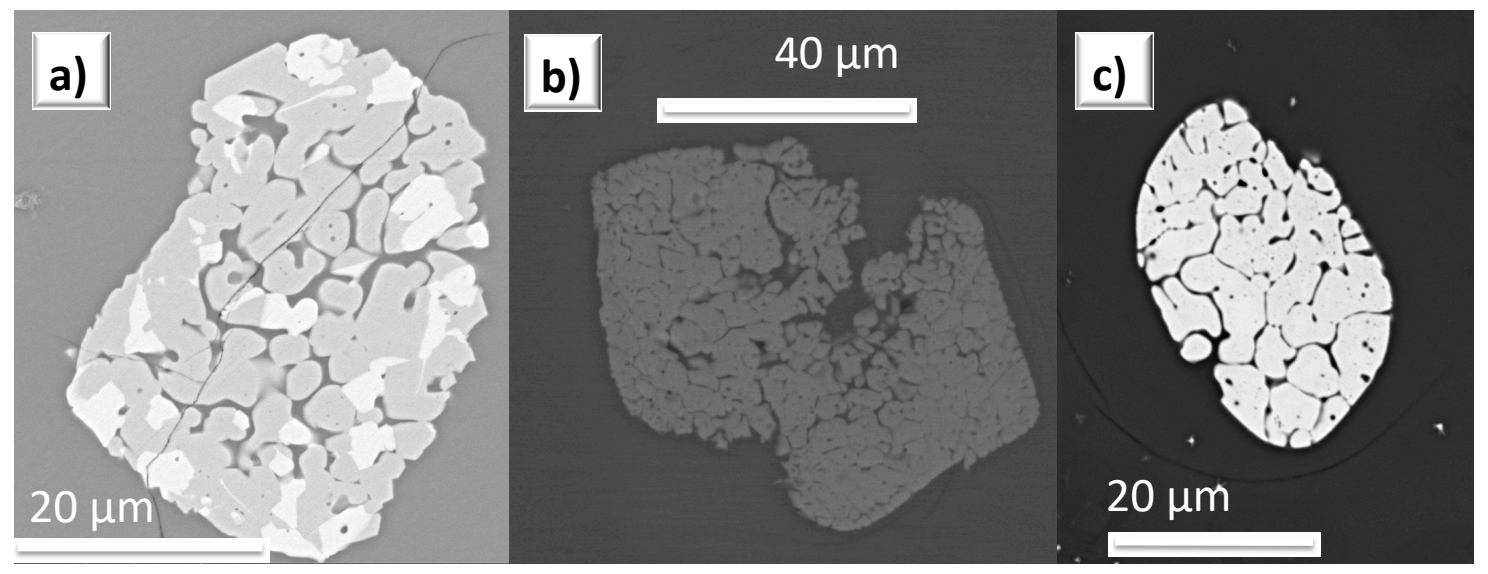

Figure 13. SEM back-scattered images of granular titanomagnetite in: (a) El'gygytgyn glass after [38]. Note that the darker phase is $\mathrm{TiO}_{2}$-rich; (b) irghizite from [12]; (c) Pantasma glass from [11]. 


\section{Synthesis}

The origin of the observed dichotomy in magnetic properties and oxidation ratio between paramagnetic glasses (five tektite strewn-fields, Darwin glass and urengoites) and the other partly ferromagnetic impact glasses (from 17 different craters) call for a fundamental difference in formation processes. The source material of tektites, being at the Earth surface with significant soil or continental sediment component [35], should initially have a large $\mathrm{Fe}^{3+} / \mathrm{Fe}^{\text {tot }}$ ratio. Various hypotheses were put forward in [9] to explain the reduction endured by tektites including the effect of very high temperature and pressure, degassing of sulfur or mixing with reducing material (e.g., carbon). Another hypothesis may be put forward here, with the eventual high temperature equilibration of tektites in near zero pressure during high altitude flight, resulting in oxygen evaporation. We note that we have possibly three cases where we can compare distal glasses (tektite) with proximal glasses deriving from the same crater: Ries glass bombs or melt with respect to moldavites; Bosumtwi melts with respect to ivoirites; Pantasma glass with respect to belizites, assuming that their proposed common origin from Pantasma crater is firmly established in the future [11]. The present review shows that the proximal glasses of Ries and Pantasma are partly ferromagnetic and oxidized with large difference in susceptibility and ferromagnetic content with respect to their corresponding tektites (Tables 1 and 3). Concerning Bosumtwi glasses, the rock magnetic measurements reported in the literature are sparse, and unclear in terms of a susceptibility difference. However, significant natural or saturation remanence is reported in $[20,58,59]$, supporting the hypothesis that Bosumtwi glass is oxidized compared to ivoirite. Still, the 'long distance flight' model does not account for the reduced character of Darwin glass.

One may question the possible use of magnetic measurements to distinguish impact glasses from other glasses produced by volcanism, lightning, pyrometamorphism (coal, hydrocarbon, and vegetation fire; see [1]) and human activity. The presence of metal for example cannot be taken as a proof for interaction with extraterrestrial matter (as described in $[48,49,56,57])$. Indeed, metal and other reduced phases of iron can be encountered in fulgurite [2], natural glass generated by vegetation fire (e.g., [60]), and of course man-made glass (e.g., [61]). As pointed out in [9], the discrimination between volcanic (e.g., obsidian) and partly ferromagnetic impact glass is not straightforward. Compared to impact glasses, obsidian seldom shows dominant paramagnetism or strong frequency dependence and other indications for grain size in the superparamagnetism to single domain range. However, that is just a tendency with exceptions (e.g., [3]) thus not allowing secure discrimination. We note that the doubt expressed in our work on the natural origin of the South-Ural glass does not rely on magnetic properties.

One general feature of impact glasses is often to contain very fine magnetic grains, which is favorable for paleomagnetic applications, i.e., using the natural remanence (NRM) record of the magnetic field present during glass cooling. However, high proportion of grains near the superparamagnetic threshold can lead to an unreliable NRM record. For in situ glasses and melts (either as sheets or dikes), this has led to numerous applications to crater studies, reviewed in [6], see also [50,53]. Paleomagnetic studies of ejecta are much rarer $[19,20,52,62]$, due to the fact that directional data may not be of interest on material cooled during the flight. They have been used to test the hypothesis that the layering of Muong Nong tektite corresponds to the paleohorizontal (i.e., the liquid spread on the soil surface) in the study [62], or to obtain indications on the magnetic field intensity during glass cooling [52]. Future applications may rely on directional data in the case of flight-oriented glass, by analogy with the case of elongated cosmic spherules fallen in Antarctica [63]. In that case, it was possible to decide if the oriented spherule fell in a normal or reverse geomagnetic field.

Our review shows that impact glasses can have highly variable susceptibility, and remanence intensity ranging from negligible to basalt-like values. However, glasses found inside the crater as large masses are usually strongly magnetic, with a signal that may be higher than the host rock (see e.g., [50]). This may result in a magnetic anomaly associated with the melt sheet (see review in [64], and e.g., [65]). 


\section{Conclusions}

Using a review of literature and new measurements, in particular on four glasses from Siberia with proven or proposed impact origin (El'gygytgyn, Popigai, urengoites, and South-Ural glass) we provide a comprehensive survey of the magnetic properties of 24 different glass types, in relation with their redox state. We separated two types of behavior:

1) Purely paramagnetic behavior related to a redox state mostly restricted to $\mathrm{Fe}^{2+}$; this characterizes the five tektite distal strewn-fields (including belizites), as well as the urengoites and Darwin glass. Our study confirms the tektite-like nature of urengoites.

2) Variable ferromagnetic behavior in the other craters and glass strewn-fields, all proven or inferred (case of LDG and atacamaite) proximal ejecta as well as in situ melt sheets. Substituted magnetite in the only or dominant magnetic mineral in most cases, although metallic iron can be encountered, as well as pyrrhotite and hematite. Grain size corresponds often to the superparamagnetic or near single domain state.

This review will help in various applications of magnetic properties of impact glasses: definition of petrogenetic conditions including redox state, discrimination with glasses of other origins, paleomagnetism, magnetic anomalies.

Author Contributions: Conceptualization, writing and visualization, P.R. and N.S.B.; Investigation, P.R., N.S.B., J.G., A.K., G.G., G.O.L., and P.B.; Resources, V.L.M. and D.D.B.

Funding: This work was supported by RFBR grant no. 18-55-15014 and by Act 211 Government of the Russian Federation, agreement no. 02.A03.21.0006 and is performed according to the Russian Government Program of Competitive Growth of Kazan Federal University. Further support by grant PRC n 1975 from CNRS/RFBR and by Amidex fundation is acknowledged.

Acknowledgments: Measurements at St. Petersburg used the facilities of RC's of St. Petersburg State University Scientific Park: "Center for Diagnostics of Functional Materials for Medicine, Pharmacology and Nanoelectronics", and "Geomod". We warmly thank J. Cornec from Denver, A. Gill from Leyden Natural History Museum, L. Folco from Pisa University, B. Weiss from MIT, I.G. Fedorova from VSEGEI St Petersburg who helped us during their collection survey or provided samples for measurement in our laboratory. XAS measurements were performed during in-house beamtime, Francesco d'Acapito and LISA staff members are thanked for the provision of the beamtime. We acknowledge the help and effort of three anonymous reviewers who significantly improved the first version of the manuscript.

Conflicts of Interest: The authors declare no conflict of interest. The funders had no role in the design of the study; in the collection, analyses, or interpretation of data; in the writing of the manuscript, or in the decision to publish the results.

\section{References}

1. Glass, B.P. Glass: The Geologic Connection. Int. J. Appl. Glass Sci. 2016, 7, 435-445. [CrossRef]

2. Essene, E.J.; Fisher, D.C. Lightning Strike Fusion: Extreme Reduction and Metal-Silicate Liquid Immiscibility. Science 1986, 234, 189-193. [CrossRef]

3. Mameli, V.; Musinu, A.; Niznansky, D.; Peddis, D.; Ennas, G.; Ardu, A.; Luglie, C.; Cannas, C. Much More Than a Glass: The Complex Magnetic and Microstructural Properties of Obsidian. J. Phys. Chem. 2016, 120, 27635-27645. [CrossRef]

4. $\mathrm{Xu}, \mathrm{H} . ;$ Lee, $\mathrm{S} . ; \mathrm{Xu}, \mathrm{H}$. Luogufengite: A new nano-mineral of Fe2O3 polymorph with giant coercive field. Amer. Mineral. 2017, 102, 711-719. [CrossRef]

5. Dressler, B.O.; Reimold, W.U. Terrestrial impact melt rocks and glasses. Earth Sci. Rev. 2001, 56, 205-284. [CrossRef]

6. Gilder, S.A.; Pohl, J.; Eitel, M. Magnetic Signatures of Terrestrial Meteorite Impact Craters: A Summary. In Magnetic Fields in the Solar System; Lühr, H., Wicht, J., Gilder, S.A., Holschneider, M., Eds.; Springer: Cham, Switzerland, 2018; pp. 357-382.

7. Folco, L.; Rochette, P.; Perchiazzi, N.; d'Orazio, M.; Laurenzi, M.A.; Tiepolo, M. Microtektites from Victoria Land Transantarctic Mountains. Geology 2008, 36, 291-294. [CrossRef]

8. Glass, B.P. Tektites and microtektites: Key facts and inferences. Tectonophysics 1990, 171, 393-404. [CrossRef] 
9. Rochette, P.; Gattacceca, J.; Devouard, B.; Moustard, F.; Bezaeva, N.S.; Cournède, C.; Scaillet, B. Magnetic properties of tektites and other related impact glasses. Earth Planet. Sci. Lett. 2015, 432, 381-390. [CrossRef]

10. Sergienko, E.S.; Kosterov, A.; Kharitonskii, P.V. Two types of impact melts with contrasting magnetic mineralogy from Jänisjärvi impact structure, Russian Karelia. Geophys. J. Int. 2017, 209, 1080-1094. [CrossRef]

11. Rochette, P.; Alaç, R.; Beck, P.; Brocard, G.; Cavosie, A.J.; Debaille, V.; Devouard, B.; Jourdan, F.; Mougel, B.; Moustard, F.; et al. Pantasma: A Pleistocene circa $14 \mathrm{~km}$ diameter impact crater in Nicaragua. Meteorit. Planet. Sci. 2019, 4, 880-901. [CrossRef]

12. Starunov, V.A.; Kosterov, A.; Sergienko, E.S.; Yanson, S.Y.; Markov, G.P.; Kharitonskii, P.V.; Sakhatskii, A.S.; Lezova, I.E.; Shevchenko, E.V. Magnetic properties of tektite-like impact glasses from Zhamanshin astrobleme, Kazakhstan. In Recent Advances in Rock Magnetism, Environmental Magnetism and Paleomagnetism; Nurgaliev, D.K., Shcherbakov, V.P., Kosterov, A., Spassov, S., Eds.; Springer: Cham, Switzerland, 2019; pp. 445-465.

13. Deutsch, A.; Ostermann, M.; Masaitis, V.L. Geochemistry and neodymium-strontium isotope signature of tektite-like objects from Siberia (urengoites, South-Ural glass). Meteorit. Planet. Sci. 1997, 32, 679-686. [CrossRef]

14. Sigamony, A. The magnetic behavior of a tektite. Proc. Acad. Sci. India 1944, A20, 15-17. [CrossRef]

15. Senftle, F.E.; Thorpe, A. Magnetic susceptibility of tektites and some other glasses. Geochim. Cosmochim. Acta 1959, 17, 234-247. [CrossRef]

16. Glass, B.P.; Koeberl, C.; Blum, J.D.; Senftle, F.; Izett, G.A.; Evans, B.J.; Thorpe, A.N.; Povenmire, H.; Strange, R.L. A Muong Nong-type Georgia tektite. Geochim. Cosmochim. Acta 1995, 59, 4071-4082. [CrossRef]

17. Senftle, F.E.; Thorpe, A.N.; Sullivan, S. Magnetic properties of microtektites. J. Geophys. Res. 1969, 74, 6825-6833. [CrossRef]

18. Senftle, F.E.; Thorpe, A.N.; Grant, J.R.; Hildebrand, A.; Moholy-Nagy, H.; Evans, B.J.; May, L. Magnetic measurements of glass from Tikal, Guatemala: Possible tektites. J. Geophys. Res. 2000, 105, 18921-18925. [CrossRef]

19. De Gasparis, A.A. Magnetic Properties of Tektites and Impact Glasses. Ph.D. Thesis, The University of Pittsburgh, Pittsburgh, PA, USA, 1973.

20. Donofrio, R.R. The Magnetic Environment of Tektites. Ph.D. Thesis, The University of Oklahoma, Norman, OK, USA, 1977.

21. Werner, T.; Borradaile, G.J. Homogeneous magnetic susceptibilities of tektites: Implications for extreme homogenization of source material. Phys. Earth Planet. Inter. 1998, 108, 235-243. [CrossRef]

22. D'Acapito, F.; Lepore, G.O.; Puri, A.; Laloni, A.; La Mannna, F.; Dettona, E.; De Luisa, A.; Martin, A. The LISA beamline at ESRF. J. Synchrotron Radiat. 2019, 26, 551-558. [CrossRef]

23. Puri, A.; Lepore, G.O.; Acapito, F. The New Beamline LISA at ESRF: Performances and Perspectives for Earth and Environmental Sciences. Condens. Matter 2019, 4, 12. [CrossRef]

24. Lee, P.A.; Citrin, P.H.; Eisenberger, P.T.; Kincaid, B.M. Extended X-ray absorption fine structure - its strengths and limitations as a structural tool. Rev. Mod. Phys. 1981, 53, 769-806. [CrossRef]

25. Ravel, B.; Newville, M. ATHENA, ARTEMIS, HEPHAESTUS: Data analysis for X-ray absorption spectroscopy using IFEFFIT. J. Synchrotron Rad. 2005, 12, 537-541. [CrossRef] [PubMed]

26. Wilke, M.; Farges, F.; Petit, P.E.; Brown, G.E.; Martin, F. Oxidation state and coordination of Fe in minerals: An Fe K-XANES spectroscopic study. Amer. Mineral. 2001, 86, 714-730. [CrossRef]

27. Giuli, G.; Pratesi, G.; Cipriani, C.; Paris, E. Iron local structure in tektites and impact glasses by extended $\mathrm{X}$-ray absorption fine structure and high-resolution X-ray absorption near-edge structure spectroscopy. Geochim. Cosmochim. Acta 2002, 66, 4347-4353. [CrossRef]

28. Giuli, G.; Paris, E.; Hess, K.U.; Dingwell, D.B.; Cicconi, M.R.; Eckhout, S.G.; Fehr, K.T.; Valenti, P. 2011 XAS determination of the Fe local environment and oxidation state in phonolite glasses. Amer. Mineral. 2011, 96, 631-636. [CrossRef]

29. Giuli, G.; Eeckhout, S.G.; Cicconi, M.R.; Koeberl, C.; Pratesi, G.; Paris, E. Iron oxidation state and local structure in North American tektites. In Large Meteorite Impacts and Planetary Evolution IV; Gibson, R., Reimold, W.U., Eds.; Geological Society of America: Boulder, CO, USA, 2010; Special Paper 465; pp. 645-652. [CrossRef] 
30. Giuli, G.; Pratesi, G.; Eeckhout, S.G.; Koeberl, C.; Paris, E. Iron reduction in silicate glass produced during the 1945 nuclear test at the trinity site (Alamogordo, New Mexico, USA). In Large Meteorite Impacts and Planetary Evolution IV; Gibson, R., Reimold, W.U., Eds.; Geological Society of America: Boulder, CO, USA, 2010; Special Paper 465, Chapter 32; pp. 653-660. [CrossRef]

31. Giuli, G.; Cicconi, M.R.; Stabile, P.; Trapananti, A.; Pratesi, G.; Cestelli-Guidi, M.; Koeberl, C. New Data on the Fe Oxidation State and Water Content of Belize Tektites. In Proceedings of the $45^{\text {th }}$ Lunar and Planetary Science Conference, The Woodlands, TX, USA, 17-21 March 2014; LPI: Houston, TX, USA, 2014. LPI Contribution No. 1777. p. 2322.

32. Chao, E.C.T.; Dwornik, E.J.; Littler, J. New data on the nickel-iron spherules from south-east Asian tektites and their implications. Geochim. Cosmochim. Acta 1964, 28, 971-980. [CrossRef]

33. Ganapathy, R.; Larimer, J.W. Nickel-iron spherules in tektites: non-meteoritic origin. Earth Planet. Sci. Lett. 1983, 65, 225-228. [CrossRef]

34. Kleinmann, B. Magnetite bearing spherules in tektites. Geochim. Cosmochim. Acta 1969, 33, 1113-1120. [CrossRef]

35. Rochette, P.; Braucher, R.; Folco, L.; Horng, C.S.; Aumaître, G.; Bourlès, D.L.; Keddadouche, K. 10Be in Australasian microtektites compared to tektites: Size and geographic controls. Geology 2018, 46, 803-806. [CrossRef]

36. Masaitis, V.L. Impact structures of northeastern Eurasia: the territories of Russia and adjacent countries. Meteorit. Planet. Sci. 1999, 34, 691-711. [CrossRef]

37. Gurov, E.P.; Koeberl, C. Shocked rocks and impact glasses from the El'gygytgyn impact structure, Russia. Meteorit. Planet. Sci. 2004, 39, 1495-1508. [CrossRef]

38. Pittarello, L.; Koeberl, C. Petrography of impact glasses and melt breccias from the El'gygytgyn impact structure, Russia. Meteorit. Planet. Sci. 2013, 48, 1236-1250. [CrossRef]

39. Masaitis, V.L. Popigai Impact Structure and Its Diamond-Bearing Rocks, 1st ed.; Springer: Cham, Switzerland, 2019. [CrossRef]

40. Whitehead, J.; Grieve, R.A.F.; Spray, J.G. Mineralogy and petrology of melt rocks from the Popigai impact structure, Siberia. Meteorit. Planet. Sci. 2002, 37, 623-647. [CrossRef]

41. Rochette, P.; Gattacceca, J.; Chevrier, V.; Lorand, J.P. Matching Martian crustal magnetization and meteorite magnetic properties. Meteorit. Planet. Sci. 2005, 40, 529-540. [CrossRef]

42. Masaitis, V.L.; Ivanov, M.A.; Ezersky, V.A.; Kozlov, V.S.; Reshetnyak, N.B. Finds of Tektite Glasses in West Siberia. In Proceedings of the Lunar and Planetary Science Conference, Houston, TX, USA, 14-18 March 1988; Volume 19, p. 728.

43. Beran, A.; Koeberl, C. Water in tektites and impact glasses by Fourier-transform infrared spectroscopy. Meteorit. Planet. Sci. 1997, 32, 211-216. [CrossRef]

44. Dunlap, R.A.; McGraw, J.D. A Mössbauer effect study of Fe environments in impact glasses. J. Non-Cryst. Solids 2007, 353, 2201-2205. [CrossRef]

45. Giuli, G.; Paris, E.; Pratesi, G.; Koeberl, C.; Cipriani, C. Iron oxidation state in the Fe-rich layer and silica matrix of Libyan Desert Glass: A high-resolution XANES study. Meteorit. Planet. Sci. 2003, 38, 1181-1186. [CrossRef]

46. Koroteev, V.A.; Loginov, V.N.; Masaitis, V.L.; Kozlov, V.S.; Boriskov, F.F. Tektite from Astaf'evskaya Placer Deposit, Southern Urals. Proc. Rus. Mineral. Soc. 1994, 123, 44-48. (In Russian)

47. Kravstova, A.N.; Guda, L.V.; Guda, A.A.; Trigub, A.L.; Badyukov, D.D.; Soldatov, A.V. Iron oxidation state of impact glasses from the Zhamanshin crater studied by X-ray absorption spectroscopy. Rad. Phys. Chem. 2019, (in press). [CrossRef]

48. Chao, E.C.T.; Dwornik, E.J.; Merrill, C.W. Nickel-iron spherules from Aouelloul glass. Science 1966, 154, 759-760. [CrossRef]

49. Hamman, C.; Hecht, L.; Ebert, M.; Wirth, R. Chemical projectile-target interaction and liquid immiscibility in impact glass from the Wabar craters, Saudi Arabia. Geochim. Cosmochim. Acta 2013, 121, 291-310. [CrossRef]

50. Pesonen, L.; Marcos, N.; Pipping, F. Palaeomagnetism of the Lappajärvi impact structure, western Finland. Tectonophysics 1992, 216, 123-142. [CrossRef]

51. Misra, S.; Newsom, H.E.; Shyam Prasad, M.; Geissman, J.W.; Dube, A.; Sengupta, D. Geochemical identification of impactor for Lonar crater, India. Meteorit. Planet. Sci. 2009, 44, 1001-1018. [CrossRef] 
52. Weiss, B.P.; Pedersen, S.; Garrick-Bethell, I.; Stewart, S.B.; Louzada, K.L.; Maloof, A.C.; Swanson-Hysell, N.L. Paleomagnetism of impact spherules from Lonar crater, India and a test for impact-generated fields. Earth Planet. Sci. Lett. 2010, 298, 66-76. [CrossRef]

53. Hervé, G.; Gilder, S.; Marion, C.L.; Osinski, G.R.; Pohl, J.; Petersen, N.; Sylvester, P.J. Paleomagnetic and rock magnetic study of the Mistastin Lake impact structure: Implications for geomagnetic perturbation and shock effects. Earth Planet. Sci. Lett. 2015, 417, 151-163. [CrossRef]

54. Wasson, J.T. Large aerial bursts: an important class of terrestrial accretionary events. Astrobiology 2003, 3, 163-179. [CrossRef] [PubMed]

55. Cavosie, A.J.; Timms, N.E.; Ferrière, L.; Rochette, P. FRIGN zircon, the only terrestrial mineral diagnostic of high-pressure and high-temperature of shock deformation. Geology 2018, 46, 891-894. [CrossRef]

56. Gibbons, R.V.; Horz, F.; Thompson, T.D.; Brownlee, D.E. Metal spherules in Wabar, Monturaqui, and Henbury impactites. In Proceedings of the Seventh Lunar Science Conference, Houston, TX, USA, 15-19 March 1976; pp. 863-880.

57. Fazio, A.; D'Orazio, M.; Cordier, C.; Folco, L. Target-projectile interaction during impact melting at Kamil Crater, Egypt. Geochim. Cosmochim. Acta 2016, 180, 33-50. [CrossRef]

58. Plado, J.; Pesonen, L.J.; Koeberl, C.; Elo, S. The Bosumtwi meteorite impact structure, Ghana: A magnetic model. Meteorit. Planet. Sci. 2000, 35, 723-732. [CrossRef]

59. Elbra, T.; Kontny, A.; Pesonen, L.; Schleifer, N.; Schell, C. Petrophysical and paleomagnetic data of drill cores from the Bosumtwi impact structure, Ghana. Meteorit. Planet. Sci. 2007, 42, 829-838. [CrossRef]

60. Roperch, P.; Gattacceca, J.; Valenzuela, M.; Devouard, B.; Lorand, J.-P.; Arriagada, C.; Rochette, P.; Latorre, C.; Beck, P. Surface vitrification caused by natural fires in Late Pleistocene wetlands of the Atacama Desert. Earth Planet. Sci. Lett. 2017, 469, 15-26. [CrossRef]

61. Ghilardi, M.; Colleu, M.; Pavlopoulos, K.; Fachard, S.; Psomiadis, D.; Rochette, P.; Demory, F.; Knodell, A.; Triantaphyllou, M.; Delanghe-Sabatier, D.; et al. Geoarchaeology of Ancient Aulis (Boeotia, Central Greece): Human occupation and Holocene landscape changes. J. Archaeol. Sci. 2013, 40, 2071-2083. [CrossRef]

62. De Gasparis, A.A.; Fuller, M.; Cassidy, W. Natural remanent magnetism of tektites of the Muong-Nong type and its bearing on models of their origin. Geology 1975, 3, 605-607. [CrossRef]

63. Suavet, C.; Gattacceca, J.; Rochette, P.; Folco, L. Constraining the age of micrometeorites using their paleomagnetic record. Geology 2011, 39, 123-126. [CrossRef]

64. Pilkington, M.; Grieve, R.A.F. The geophysical signature of terrestrial impact craters. Rev. Geophys. 1992, 30, 161-181. [CrossRef]

65. Quesnel, Y.; Gattacceca, J.; Osinski, G.; Rochette, P. Origin of the central magnetic anomaly at the Haughton impact structure, Canada. EPSL 2013, 367, 116-122. [CrossRef] 